\title{
The Observational Socio-Economic Study and Impact on the International Innovative Leadership in the United States
}

\author{
https://doi.org/10.21272/sec.4(4).63-94.2020
}

Karina Kasztelnik, ORCID: https://orcid.org/0000-0002-1090-3700

PhD MBA, CPA, CTP, Professor of Accounting, Grand Canyon University, Washington, DC, USA

Damon Brown, Ed.D. MBA, Training Coordinator, Department of State, Arlington, VA, USA

\begin{abstract}
This paper summarizes how socio-economic study has impact on the international innovative leadership in the United States. This article includes the review will focus and examine literature and theories related to public policy organizational effectiveness as well as diversity leadership. Online databases including search engines located relevant books, journals, articles, and dissertations. The search terms used were descriptive of various themes such as diversity, diversity leadership, public policy and public policy leadership, organizational leadership, public policy and leadership, cultural diversity, organizational effectiveness, and public policy effectiveness. Additionally, measurements of public policy organizations effectiveness have been narrowly focused on past practice failing to include multiple organizational aspects similar to other professional organizations. Prior studies have been conducted in relationship to the effects of diversity leadership and leadership although related solely to the individual officer or the public policy organization. Notwithstanding, studies have been sparse which suggest that diversity leadership initiatives or enhanced leadership, increase public effectiveness, let alone collectively. Limited studies are not the case concerning public policy. This study attempted to fill this gap by examining if leadership of public policy outcomes of diversity leadership initiatives and the level of leadership predicts public policy organizational effectiveness. All of these terms have assisted in locating contemporary and relevant research. The results of the critical review article with analysis both authors can be useful for any leaderships around the World to support social-economics changes.
\end{abstract}

Keywords: socio-economic, innovation, leadership, education, public policy.

JEL Classification: A19, A10, D69.

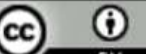

Cite as: Karina Kasztelnik, K., Brown, D. (2020). The Observational Socio-Economic Study and Impact on the International Innovative Leadership in the United States. SocioEconomic Challenges, 4(4), 63-94. https://doi.org/10.21272/sec.4(4).63-94.2020.

(C) The Authors, 2020. This article is published with open access at Sumy State University.

\section{Introduction}

Scholars argue that the absence of broader performance measures limit the effectiveness of public policy (Knight, 2014) although; varied perspectives of organizational effectiveness create issues for those seeking to evaluate the effectiveness of an organization (Kiehl, 2013). In the past, the minimal indices of public policy effectiveness exemplified establishing control, protecting life and property, and avoiding injuries to the public policy themselves (Fielding, 1988). Public policy organizations measure of effectiveness have varied and are not inclusive of the very practices that lead to effectiveness as it relates to modern day communities. The problem that public policy officials in the past have struggled with is embracing the broader practice of effectiveness, where they focus on the reporting of performance measures rather than on using them for improving service delivery to the community (Rivenbark, Roenigk, \& Noto, 2013). Organizational effectiveness has in the past been a broader term for encompassing multiple constituents for measuring organizational performance (Kataria et al., 2013). 
Only scholarly peer-reviewed articles were used to create the foundation of this review., Google Scholar and the online database Questia, identified peer-reviewed books, journals, and articles. The ProQuest dissertation abstract database located dissertations whereas pertinent information resided particularly, within the abstracts, literature reviews, conclusions and findings of the various dissertations selected for this literature reviews. All relevant books, journals, articles, and dissertations are categorized according to their publishing research dates, giving preference to those, published in the last five years.

Using the resources above and relevant information within, will confer that the development of diversity leadership initiatives and leadership pursuing public policy effectiveness will allow public policy to build a foundation for legitimate and genuine relationships with all communities. Many studies have suggested that to be effective; public policy must re-establish a credible relationship with the communities they serve but have failed to address detailed procedures for doing so. Past studies have also suggested that public policy should increase community-policing efforts as a response to the poor or non-existent relationships in those communities. These studies outlined specific community policing activities in which the public policy can engage in but have often failed to address the specific knowledge, skills, and abilities that public policy officers must acquire to accomplish the recommended community policing efforts successfully.

Over 200 studies relating to public policy effectiveness measurements, including some relating to performance measurement more generally have been conducted (Tiwana, et al, 2015). These studies have not specifically studied the relationship of diversity leadership initiatives and leadership as it relates to public policy effectiveness. Garib (2013) concluded that a more advanced study would advantageously include improved methodological activities resulting in some objective data concerning organizational outcomes of diversity leadership. While Carrizales et al. (2016) assert that future research may look at the integration of cultural competency into public policy organizations and how its service delivery will make it a more effective public administration. Furthermore, this study examined if the leadership of public policy agencies high level of learning outcomes of diversity leadership initiatives combined with high level of leadership of leadership relates to a higher level of public policy organizational effectiveness than either leadership's learning outcomes of diversity leadership initiatives or leadership alone. Diaz et al. (2015) suggest that research among interdisciplinary professionals is needed to identify and facilitate a more culturally competent and diversity educated workforce in order to possibly increase effective practices. The target population for the study was AACPD in Maryland specifically, Sergeants Lieutenants, Captains, Majors, Commanders, Assistant Chiefs, Deputy Chiefs, and Chief. Public policy effectiveness will then be described as a wide organizational construct similarly to other professions as opposed to small or single measurements, which have been utilized terribly in the past.

\section{Theoretical Framework}

As demographics within the nation continue to evolve, there is a need for public policy to continue to find various strategies and solutions to what seems to be an insurmountable amount of complex problems to be effective in the communities they serve. Public policy has been the focus of criticism encountering ongoing problems over the existence of American policing which neither the public policy themselves or the community have been able to address. Hence, this literature review will place recent developments in ideology of policing in perspective drawn from Complexity of Problem Theory (CPT).

The Complexity of Problem Theory within the publication, Public policy Problems: The Complexity of Problem Theory, Research and Evaluation developed by John Eck (2003) propositions that public policy problems be addressed by answering four core and fundamental questions paralleling the SARA (Scanning, Analysis, Response and Assessment) problem-solving process. Insomuch, the CPT is appropriate to be employed this particular study. Overall, CPT distinguishes problem-oriented policing, which should not be confused with community policing. CPT can be applied to any public policy problem.

In this research, CPT is the foundational lens in which we view and investigate the issue of increasing public policy effectiveness by way of diversity leadership and leadership. There is a significant difference between public policy and citizen perceptions of public policy effectiveness (Ward, 2013). To be effective both the public policy and citizens of the community must agree upon what is effective policing, meeting the needs of the public. 
Cross-cultural adaptability meets the public's needs and represents an opportunity for public policy organizations to move toward becoming more culturally proficient (Elton, 2013). The problem of realizing public policy effectiveness is of critical concern, the efficacy of public policy means public policy are meeting the needs of the community. Both public policy and citizens perspectives are relevant albeit the community's perception is of primary concern given that public policy are public servants who are to serve the public and not themselves. Policing is a profession even supposing the public policy cannot suggest that they know what is best for the community. Policing then includes understanding what mechanisms can assist them in serving the community and being effective in applying them.

Organizational effectiveness in professional organizations includes a component of customer service. Policing claims to be a profession therefore, public policy cannot exclude the aspect of customer service. In this case, the communities are the customers. Customer satisfaction is contingent upon meeting the client's needs. Multicultural communities have an assortment of needs in which public policy continually attempt to address. Meeting these requirements can only be done effectively by an increased knowledge of the diverse cultures that they currently serve.

Diversity in public policy in this study will speak on two fronts, the actual diversity of public policy officers and the diversity each officer faces in today's multi-cultural communities. There is a gap in the literature as to if leadership, which Halla (2014) theory explains, increases our ability to interact meaningfully with people of other cultures, leads to public policy effectiveness. The research was conducted to ascertain if diversity leadership initiatives and leadership both separately and combined will predict public policy organizational effectiveness once endorsed by leadership and, if both or, either will be a major contributing factor to public policy organizational effectiveness, particularly from the viewpoint of public policy leaders.

Diversity leadership within public policy agencies is not without limitations, for example; if not embraced by the hierarchy, diversity leadership may not be worth the effort. Although, scholars suggest that more research needs to directly examine the casual linking of learning outcomes of diversity leadership with organizational outcomes (King et al. (2012). Cunningham (2012) referring to diversity leadership mentions that; there is a need to further examine through research, the possibilities of when and under what conditions diversity leadership improves organizational performance. This gap and suggestions for further research are imperative as the communities that public policy serve become more diverse.

Cultural competency can be measured using various tools and self-assessment mechanisms. Fletcher (2014) mentions that additional research is needed to develop an understanding of how increased knowledge of leadership will affect organizational capacity leading to increased organizational effectiveness. Schutte (2014) contends that future research should focus on leadership leadership that is effective in improving leadership for practitioners that translates to better outcomes for clients increasing organizational efficacy.

The study examined if leadership of public policy agencies learning outcomes of diversity leadership initiatives and the level of leadership of leadership predicts public policy organizational effectiveness. Garib (2013) concluded that a more advanced study would advantageously include improved methodological activities resulting in some objective data concerning organizational outcomes of diversity leadership. While Carrizales et al. (2016) assert that future research may look at the integration of cultural competency into public policy organizations and how its service delivery will make it a more effective public administration. Furthermore, this study examined if the leadership of public policy agencies high level of learning outcomes of diversity leadership initiatives combined with high level of leadership of leadership predicts to a higher level of public policy organizational effectiveness than either leadership's learning outcomes of diversity leadership initiatives or leadership alone. Diaz et al. (2015) suggest that research among interdisciplinary professionals is needed to identify and facilitate a more culturally competent and diversity educated workforce in order to possibly increase effective practices which, was done by researching cultural competency of officers and how diversity leadership initiatives related to public policy effectiveness (Figure 1). The target population for the study was AACPD in Maryland specifically, Sergeants Lieutenants, Captains, Majors, Commanders, Assistant Chiefs, Deputy Chiefs, and Chief. The research addressed the problem of effectiveness. 
The CPT also suggests that research and evaluation can improve the practice of policing through a problemoriented policing strategy, applied by community organizations, government agencies, with or without the public policy (Eck, 2003). Two problems are presented. The overall problem of poor or non-existent public policycommunity relationships and, the issue of increasing public policy effectiveness through diversity leadership and leadership, which is the study's focus. Eck's (2003) CPT insists that a research agenda be created to address problems of the public policy by answering four fundamental questions: "What are problems? What causes problems? How can we find effective solutions to problems? Moreover, how can we learn from problem solving?" (p.79).

As the literature review will demonstrate, increasing public policy effectiveness is a problem, and the research attempted to critically address this issue through evaluating it by investigating how it is related or not, by diversity leadership initiatives and leadership. The policing profession would significantly address the problem of establishing a genuine relationship with the communities they serve by enhancing and justifying additional resource allocation towards diversity leadership and leadership founding it to be related to public policy effectiveness. The relationship between public policy and community may benefit by constant analysis.

Addressing the relationship between public policy and the communities they serve, specifically Black and multicultural communities is essential to effective policing. In this sense, public policy recognizes that there is a problem in public policy treatment of minorities mainly within the very communities they reside but are taking some steps to address it (Woods, 2014). The current tumultuous environment leaves many public policy officers perplexed defaulting back to the single focus of maintaining law and order. This narrow context often exasperates multicultural communities because of the perceptions or reality of unequal treatment and a lack of understanding of the daily strife minorities' encounter. Sparrow (2015) explains this relationship explicitly:

Residents of poor and minority community neighborhoods with serious disorder problems often have antagonistic relations with the public policy. They regard the public policy as another of their problems; frequently perceive them to be arrogant, brutal, racist, and corrupt. (p. 13)

Forcing or coercing public policy relations will not be successful. CPT suggests that the problem addressed in this study, enhancing public policy and community relations, is deconstructed through research in the effort that public policy better understand the problem at hand. The initial framework of CPT is to develop problem-oriented policing to address the various challenges public policy face. The reliance of problem-oriented public policy is paramount to the CPT although it may also be the theory's Achilles' heel. With all of the problems that public policy face today it is questionable if policing has the stamina to address the overwhelming amount of its problems. In response, CPT recommends that increasing systematic information exchange among public policy agencies be part of the answer (Eck, 2003). A researcher sharing their findings in regard to specific problems through a comprehensive mechanism all public policy can access is an operable strategy.

As a potential antidote addressing the problem in this study, including diversity leadership and enhancing the leadership of officers can serve as an initiator to establishing a genuine relationship with multicultural communities. The two are related to increasing effectiveness of public policy. Insomuch, public policy agencies across the nation could develop a viable strategy to incorporate both diversity leadership and leadership, which could not only increase organizational effectiveness but change the dynamics of the public policy-community relationship significantly.

Therefore, the literature review presents the following topics in sections with subtopics to be covered and discussed explicitly. Each of these sections is composed of subsections. To facilitate an in-depth understanding of the solutions to the problem of increasing public policy effectiveness, employed is the foundational theory framework of the CPT, particularly the third fundamental question. The third question is essential in this study and understanding this literature review; how can we find effective solutions to problems? In this research as previously mentioned, increasing public policy effectiveness is the problem. The study investigates and reviews the literature of diversity leadership initiatives and leadership further establishing a theoretical framework for future research. 
The first section is diversity-leadership initiatives subtopics within are, understanding/accepting diversity and leadership, outcomes and effects. The second section of leadership includes subtopics, leadership in the public policy and enhancing leadership. The last section of the literature review is public policy effectiveness with subtopics, public policy organizational efficacy and measures and models of effectiveness.

\section{Review of the Literature}

A properly structured literature review provides context for the study and establishes a structure for the information within. The literature review provides the theoretical framework and research-based grounding for the study (Pemberton, 2012). The design of the literature review is critical; it is intended to provide an in-depth understanding of the research study for the reader who is unfamiliar with the topic of the study. It is designed to flow sequentially establishing the purpose of the research and why it is important. Concluding each major section with a summary that ties the literature back to purpose and significance of the study makes clear to the reader why the literature just read is important and relevant (Pemberton, 2012). Equally important, the summary of each section will include a brief synopsis of valid points, strengths, weaknesses and applicability of the study.

This literature review will espouse literature on effectiveness from the position whereas public policy organizations are in fact organizations. The same metrics of effectiveness used by other agencies regardless of the nature of their business to measure effectiveness applies to law enforcement. In the past, this has not been the case as across the nation public policy organizations continue to design and establish measurements of effectiveness specific to that organization. Whether crime rate, case clearance rate, arrests or even the amount of tickets written, the measurements of public policy organizations are not standardized. The lack of standardization of organizational effectiveness measures in public policy creates ambiguity in understanding if public policy organizations are effective, particularly in comparing likewise organizations.

An extensive review of literature related to public policy effectiveness revealed three significant studies. These studies support this research topic to be explored, the effects of public policy leader's diversity management leadership initiatives and leadership on perceived effective policing: Legrand and Bronitt (2012), Coleman (2012). Tiwana et al. (2015), Sparrow (2015) and Tozlu and Tuzen (2016). These studies agree that the research topic is worth studying because; leadership can affect the effectiveness of the public policy and because current mechanisms and initiatives used to increase public policy effectiveness are insufficient and limited. Public policy organizations evolve and what increases effectiveness must also adapt. More importantly, public policy executives need an in-depth understanding of what leads to effectiveness particularly as it relates to the citizens they serve to pursue, achieve, and realize public policy efficacy.

Ultimately, the predictor variables of diversity leadership initiatives and leadership was added to the data separately and collectively to ascertain the effects on public policy organizational effectiveness, the criterion variable. All sections will include a definition and explanation of the variable discussed. The definition will assist in understanding the overall problem. In line with CPT, it is paramount that we address the first of four questions; what the problem is, thus beginning each section with a definition.

The initial section, diversity leadership, includes literature which speaks of what diversity is, how it is understood and accepted in an organizational context and its relevance to public policy organizations. It also presents important literature concerning the importance and reasons for why diversity leadership is necessary for policing. Leadership is paramount, but its efficacy and outcomes are the keys to the success of the leadership. Literature concerning the leadership results and its effectiveness is next. The literature is compared and contains specific measures, which may increase the outcome and effects of diversity leadership on an organization and individual.

Individual leadership is the second focus of the literature review. Leadership continues to develop literature, which stresses its importance and relevancy to interacting with diverse people and multicultural communities. The review identifies literature concerning its application to public policy organizations, initially identifying literature from other agencies narrowing the literature specifically to policing. Leadership is a continuum. The literature presented then suggests how to increase individual and organizational competence in the public policy organization through different learning mechanisms. 
Public policy effectiveness is the final section of the literature review. Effectiveness is a complicated but well thought out premise in any organization, which requires relevant measurements. Thereby organizational efficiency and its measures are included in this in-depth literature review. The in-depth review is necessary and based on the foundational theory; CPT. Without the proper knowledge included in this review, the SARA problem is not applicable the overall goal of problem-oriented policing has always been to build a knowledge base about types of problems that guide public policy action at that problem (Eck, 2003).

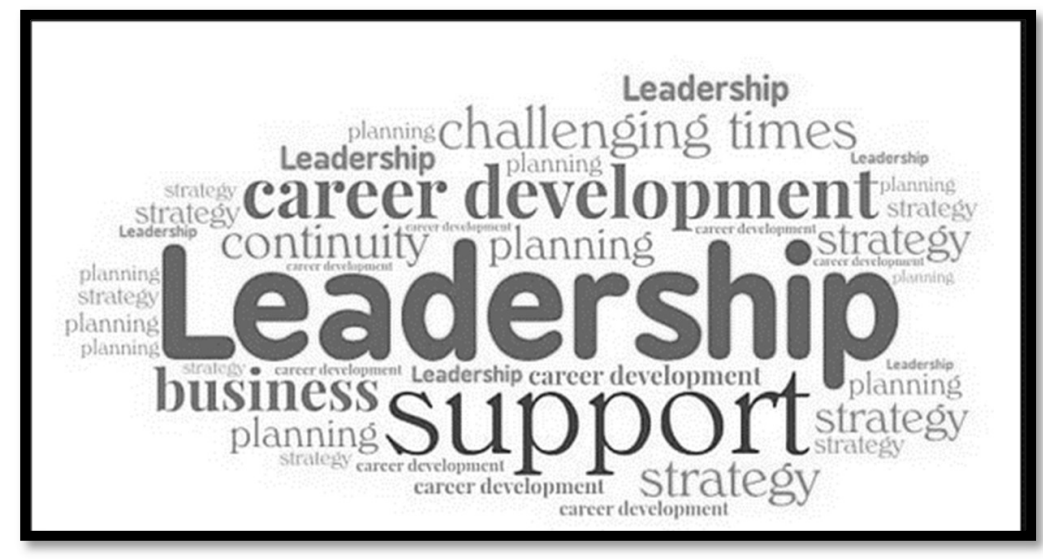

Figure 1. Leadership theory

Source: Mindwerx.com

Understanding and accepting diversity. The definition of diversity evolves as globalization continues to accelerate. The many aspects of diversity have scholars perplexed when attempting to agree on a common definition. DeGeorge (1995) insists that diversity is nothing less than an extension of affirmative action programs in the workplace. Bohm (2013) defines diversity as, visible and subjective differences between people. Seedall et al., (2014) suggest that diversity is the state of being diverse, variety, a range of different things. While the most simplistic definition, the difference between us (Lee, Chancellor, Chu, Rodriguez-Mori, \& Roy, 2015) continues to be in line with the other researchers excluding DeGeorge (1995). As the literature progresses, definitions become more complicated and inclusive of other factors. Peery, Julian, Avery and Henry (2013) explain that diversity is the development of a culture where individuals and organization move beyond simple tolerance, where they embrace and celebrate the richness of debate and dialogue based on the difference.

These definitions may not address the second of the four questions drawn from the CPT; what causes the problem? The four questions should not be confused with attempting to answer the overall problem, which is addressing the dysfunctional relationship between public policy and community. The focus is drawing from the CPT framework to address the issue of public policy effectiveness. A simple definition of diversity may be a simple response to the question above although, in this case, simplicity will not be able to address the complex construct of diversity and how it relates to effectiveness. A more comprehensive definition of diversity, which includes the various aspects surrounding the proposed research topic, would be more beneficial in this literature review and is subsequently sought and presented.

Perhaps, it is the complication and differences in defining diversity inclusive of other contexts and factors assist us in acknowledging how broad diversity is. Seedall et al. (2014) identify race, culture, ethnicity, gender, socioeconomic status, sexual orientation, ability, and religion/spirituality as the social identities most commonly associated with diversity. Seedall et al. (2014) also note that not all articles, which address issues of diversity, do so from a social justice perspective. Chin, Desormeaux, \& Sawyer (2016) references multi-cultures in defining diversity from within the multicultural literature based on principals of inclusiveness, leadership, difference and multi-cultures valuing the differences between groups and the inclusion of all groups. Over time, collective understanding of diversity has grown to include other groups, and the focus of diversity in some organizations is 
on a wider range of differences, including sexual orientation, gender identity, age, religion, nationality, work style and more (Katz \& Miller, 2016).

When diversity is explained in inclusive of terms and constructs such as socioeconomic status, gender, culture, religion, gender and social identity and they are placed within a public policy context, we reflect upon how policing was conducted during the civil rights era. Bigotry, prejudice, intolerance, racism and inequities often raised its ugly head in the form of a public policy officer seen as the agent of the government enforcing oppressive laws which impacted Black communities disproportionally, such as Jim Crow laws. Analyzing this information in the context of CPT second of four questions, what is the problem? The problem is that multicultural and particularly Black communities still see public policy in this light. The problem is defining diversity in an inclusive but not offensive model.

Applicable to the problem of how diversity is defined, Alcott (2012) theorizes that learning requirements should be specifically designed to provide incoming officers with the competencies to apply critical reflective practice, problem-solving and efficient decision-making, which are designed to increase and accept the understanding of social diversity and community engagement. Although, the literature is not convincing about this aspect. The intention is to deliver public policy officers into the operational field that can deal with members of the community in a way that provides a more considerate and proportionate service (Alcott, 2012).

By engaging in the culturally diverse activities public policy can understand diversity better than they have in the past. Ben-Porat et al. (2012) suggest that management is crucial to embracing diversity when they state that the premise of diversity management is that organizations must embrace diversity to thrive in the modern world. Mandates, as suggested above, do not satisfy today's need for diversity. The need for embracing diversity goes far beyond legislative requirements (Brecher, 2012). Zakin (2012) suggests that tolerating and accepting diversity starts with the recognition of one's self in comparison to others, which leads to an appreciation of difference and similarity.

Fleming (2012) described sharing the knowledge that he gains by accepting himself allowed him to celebrate diversity as a result connecting with others who were different. Referencing the embracing of diversity within an organizational context Brecher (2012) gives four tips for embracing differences or diversity; Prevent groupthink, broaden perspectives, generate new ideas and participate in globalization. These four tips are a viable response to the CPT third question of how can we find solutions to problems, albeit the lack of understanding diversity as an organizational goal to increase public policy effectiveness.

More recently Burke, Teague, Ward, and Worrall (2016) suggest that the embracing of diversity depends on your barometer or what diversity is, mediated by the culture of the organization. If the culture is a collectively held set of beliefs, then everyone in the organization contributes to that culture which is embracing diversity, its impact regarding values espouses a demonstrative commitment to diversity and equality (Burke et al., 2016). Success goes beyond tolerance to embracing and incorporating differences according to Brecher (2012). A diverse workplace is needed for organizations to stay current with contemporary culture and move into the future (Brecher, 2012).

Again, embracing diversity addresses the third of four questions within the CPT. By embracing diversity, we are answering; how can we find effective solutions to the problem. Identifying what is diversity as a problem; specifically, in a country of multicultural communities public policy are less likely to understand diversity. Although by providing an in-depth definition and implementing strategies for embracing diversity we address the first three or four basic questions within the theory used for the proposed research study, CPT. Even though at this stage the fourth issue, how can we learn from problem solving remains to be elusive. Forecasting would suggest that this question could be answered eventually as this issue of a lack of understanding of diversity among public policy dissipates. The matter of learning from problem solving is an ambitious undertaking, but then we have some clues on how we can proceed (Eck, 2003).

The definition of diversity runs the gambit although the strength of diversity through its definition particularly from Seedall et al. (2014) who recognizes diversity as something tangible but also a construct is beneficial. Chin 
et al. (2016), Fleming (2012) and Burke et al. (2016) all suggest variables of self-identification, which can be faulty, based upon self-categorization, i.e. even though we look different we are the same. In this context, there is no diversity, so it is impossible to embrace. Alcott (2012) suggests developing a leadership curriculum that will increase competencies if officers are to be adept at handling the plethora of issues when confronted with serving diverse communities. Proceeding in this fashion demonstrates a partial or piecemeal understanding of learning from attempting to problem solve the lack of an understanding of diversity and its definition by public policy inclusive of social constructs.

Seedall et al. (2014) then offers the most objective definition of diversity for this study as it limits variation and is applicable and inclusive of social constructs. Applicable to this study, Alcott (2012) theorizes that learning requirements should be specifically designed to provide incoming officers with the competencies to apply critical reflective practice, problem-solving and efficient decision-making, which are designed to increase and accept the understanding of social diversity and community engagement although, literature is not convincing in this aspect.

Leadership, outcomes, and effects. A major concern and question arises when discussing diversity; how we can make diversity a viable part of our culture. Some of the greatest challenges to achieving diversity and inclusion in our educational institutions are getting leadership and faculty to model cultural differences and mentor students (White, Louis, Persky, Howell, Griffin, Simmons-Yon, \& Scolaro, 2013). White et al. (2013) theorize that to achieve societal diversity and inclusion, a multifaceted effort is required, involving a continuum of institutional strategies, including innovative models and other high impact programs.

The researchers above suggest challenges in realizing diversity-leadership initiatives. Many pre-service and current teachers simply do not understand what multicultural education is or looks like (Freeman, Izzard, Faulkner, $\&$ Charles, 2012). Credibility may lie with teachers in schools and universities educated in diversity and multicultural education themselves. Freeman et al. (2012) mention that the candidate teacher population in many educational programs is approximately $70 \%$ Caucasian in many parts of the country. White et al. (2013) suggest that the road to diversity initiatives is through our leadership in educational institutions. Freeman et al. (2012) offer that it is the teachers themselves who cannot apply diversity initiatives because of their lack of education in the subject matter which may or may not be related to their race but this assertion from Freeman et al. (2012) does not dismiss that diversity leadership initiatives must begin in our educational institutions.

The intended result of diversity leadership is to change behaviors. Returning to the foundational theory of what the proposed research is drawn from, CPT includes a behavioral dimension. This behavioral dimension is related to the last of the four questions emphasized in theory; how can we learn from problem solving. Learning from problems solving and uniformly applying it, we must use learning institutions as a mechanism. The suggestion of formally educating public policy through learning institutions allows public policy to learn from post problem solving. Within the CPT, the behavioral dimension is important because it draws attention to the way public policy act, the interaction among participants in a problem, and their motivations (Eck, 2003).

Development and implementation of a comprehensive institutional strategy intended to create an inclusive educational environment must be implemented to ensure diversity and racial inclusion among our educators (White et al., 2013). Program initiatives must be implemented to attract students from a variety of ethnic and cultural backgrounds, focusing on increasing the number of minority and underrepresented individuals who apply, are admitted, matriculated and graduate (White et al., 2013). This proposed template offers constructive advice for diversity initiatives within public policy departments and their learning institution.

Public policy leadership within public policy academies equates to a learning institution despite its questionable efficacy complicating the proposed research. Investigating the impact of diversity leadership on public policy effectiveness, one assumes that the learning mechanisms selected are capable and efficient in leadership resulting in positive leadership outcomes. Public policy academies continue to be the venues where public policy departments receive their education and instruction. Birzer (1999) suggests that most public policy academies conduct leadership using a lecture format, which emphasizes obedience and does not encourage effective learning. The aforementioned supports Beu and Nepravishta (2013) suggesting that the challenges of the public policy education system face some obstacles of formation type, which lead to a lack of the public policy education to 
achieve university levels. Insomuch, understanding that educational institutions have considerable challenges in creating strategies to include diversity, public policy academies equally have challenges in achieving effective learning, which rises to the level of universities.

Birzer (1999) and Rice and White Roberts (2010) assert that diversity leadership is needed; Cultural diversity represents an important area that public policy trainers must include in the curricula (Birzer, 1999). Cadets must receive a clear message at this early stage that racially biased policing is inappropriate, illegal, and is not tolerated (Rice \& White Roberts, 2010). The gap between effectiveness and diversity leadership will be investigated thoroughly and aligns closely within CPT in identifying solutions to problems, in this case, effectiveness by way of increasing diversity. CPT emphasizes this when Eck (2003) insists that removing vague concerns and requiring specificity enhances problem analysis and solution identification.

Researchers outline several problems with diversity leadership, which will be considered in the proposed study. Diversity-leadership initiatives rarely incorporate the experience of unequal treatment (King et al. (2012). The salient feature of evaluating diversity leadership for effectiveness is questionable. Soldan and Nankervis (2014) mentioned that diversity leadership could not be easily tested, observed or assessed. A lack of measurements is not related to organizational commitment. Soldan and Nankervis (2014) suggests transforming the organization's commitment to diversity leadership and management. Organizational action resulting in effectiveness espouses a gap between how diversity leadership and management is practiced (Soldan \& Nankervis, 2014). Positive outcomes of diversity leadership are of extreme importance for the proposed study. Coupled with organizational commitment particularly line managers diversity leadership provides a rough draft for realizing public policy effectiveness, the core of the proposed study.

Public policy leadership, particularly diversity leadership requires a conduit to achieve applicability. Leadership programs are not effective if line managers such as public policy Sergeants are unable to or do not transfer what they have learned to their job (Cocchiara, Connerley, \& Bell, 2010). Cocchiara et al. (2010) contend that the measure of the effectiveness of diversity leadership is dependent on Sergeants transferring what is learned in diversity leadership although this does not gauge how effective diversity leadership is despite Sergeant's influence. Seong and Doo-Seung (2013) argues that supervisors can take advantage of benefits of diversity by fostering cooperative group norms.

Soldan and Nankervis (2014) insist that evidence of whether these programs (diversity leadership) are effective in meeting their intended goals is sparse. Without nailing down the various classifications of diversity, it is difficult to measure results. A majority of appropriate diversity classifications are based on perception and are dichotomous (Simons \& Rowland, 2011). These perceptions can be mediated by how one perceives them. Garib (2013) suggests that the social categorization perspective is based on the tenet that diversity is influenced by how people can be more similar or more different than others on the basis of how they categorize themselves and others. Hurtado and Deangelo (2012) reference a series of studies conducted by the Higher Education Research Institute (HERI) at the University of California-Los Angeles, basing results on surveys administered as a part of the Cooperative Institutional Research Program (CIRP). CIRP surveys contain a comprehensive set of measures that capture not only students' civic and diversity-related experiences, but also outcomes that can be linked with educational purposeful activities by faculty and staff. According to Hurtado and Deangelo (2012), the results of the surveys show that peer environment is powerful, yet and underutilized tool for learning.

It is unknown if social identity theory applies in policing or if public policy see themselves as peers. Social identity consists of social categorizations or groups to which one perceives membership or belonging (Simmons \& Greenwell, 2014). Through these group memberships, the individual adopts the values and beliefs of the social group, which creates a social identity shared with other members of that group (Dwyer, Eddy, \& LeCrom, 2014). If seen as peers within a group, are White and Black officers from various public policy organizations that lack diversity more or less likely to be effective when it comes to the outcome of their duties? Notably, Hurtado and Deangelo (2012) theorized that having had intellectual or meaningful and honest discussions about race or ethnic relations outside of a formal setting with peers of a different race or ethnicity also contributes to the development of strong habits associated with being more diverse. 
As in any profession peers interact informally, however, the frequency and specifics of the informal interaction are unclear. This is essential to understanding the relationship of diversity leadership initiatives and how if at all that they relate to increased public policy effectiveness. The study investigated this aspect. Additionally, even though White and Black officers may see each other as peers based on the social, organizational and social identity theories, they will have various conceptions and interpretations of diversity as explained in this section. Perhaps these officers have some understanding of what diversity is to address complicated issues before diversity leadership. It is unknown if peers are affected by diversity leadership similarly. The research intended to ascertain if White and Black officers as peers increase their understanding of diversity through diversity leadership increasing effectiveness despite how they previously defined or viewed diversity based on their past experiences.

Social organization and social identity theories are important aspects relating to if diversity leadership increases the effectiveness of public policy officers as based on their interaction with peers, notwithstanding ethnicity and race. Garib (2013) insists that although people may categorize themselves as diverse, complex problems are only solved by the availability of various viewpoints, as similar viewpoints do not add significant value. Even though one's construction of the self can be comprised of a number of different identities (Matherne, Hill, \& Hamilton, 2016) which emphasize Garib (2013) contention that having different opinions based on multiple identities on a team or organization can contribute to positive outcome for all members not just the in-group.

The perspective on out-group trust is that it yields positive relationships between ethnic diversity and in-groups (Gundelach, 2014). Gundelach (2014) explains that out-group trust means trust across cultural identities, i.e. trust in people with whom one does not share and recognize a common group identity. A productive scenario presents itself when a new member has friends or acquaintances in both the in-group and out-group (Stura \& Lepadatu, 2014). Unfortunately, literature is varied with some studies supporting out-group trust leading to positive relationships recognizing and accepting diverse individuals and others do not.

Emphasizing social categorization and social identity theories in a group among peers through formal and informal interaction may result in a normalization of the group despite team members being composed of various individual differences and ethnicities regardless of sub-groups. Many social groups do include sub-groups. It is then prudent to investigate public policy as a group when researching if and how diversity-leadership initiatives predict public policy effectiveness.

White et al. (2013) study has several strengths as they suggest that diversity leadership must use a multi-faceted approach and spearheaded by leadership who must model diversity. CPT offers a capacity for multiple interventions in various contexts. Comparative to White et al. (2013) suggestion that diversity leadership being multi-faceted, Eck (2003) CPT suggests that problems require multiple interventions in multiple contexts. Another strength that White et al. (2103) asserts is that those who have an in-depth understanding of diversity conduct the leadership and that the staff instructing diversity should reflect diversity in their make-up.

Birzer (1999) and Rice and White Roberts (2010) also assert that diversity leadership is necessary although, Birzer (1999) whom study is dated, contradicts himself when he mentions diversity leadership is needed but then explains that most traditional public policy leadership at the public policy academy is ineffective. Reinforced by Beu and Nepravishta (2013) who mention that public policy-leadership fall short of desires and public policy educational institutions should aim at equivalence to diplomas, certifications or other academic recognitions of homolog academies and institutions. Birzer (1999) does not suggest who or where public policy then should train presenting a confusing and weak case of overall leadership particularly, diversity leadership.

Diversity being about classification which Garib (2013), Gundelach (2014) and Hurtado and Deangelo (2012) agree although, the strength within this context lies within literature from Hurtado and Deangelo (2012). The two reference several valuable studies related to peer interaction and the increased outcome of diversity through informal interaction and the subsequent self. Hurtado and Deangelo (2012) literature applies to this study as it more closely reflects what society is today; multicultural and diversely grouped to obtain a common organizational mission as social and organizational peers. Both White et al. (2013) and Hurtado and Deangelo (2012) studies are possibilities for the field of policing in the efforts to formalize a viable plan for positive 
outcomes of diversity leadership initiatives among the public policy. Needed is additional study and research to fully understand how the two studies can be applied instrumentally for public policy effectiveness.

Social categorization theory, the grouping of officers who are diverse and see themselves as peers may be more applicable to effectiveness operating in multicultural communities even though there is not much literature which supports this theory. Studies such as; Cocchiara et al. (2010) and Seong and Doo-Seung (2013) imply that the relevance of buy-in of diversity leadership or public policy leadership in general particularly by line managers or public policy Sergeants seem to mediate if leadership is applied and realized at the service or street level particularly, within multicultural communities.

\section{Leadership}

\section{Leadership in the public policy}

In the past there has been literature on competence, which has suggested that it is a non-contributing factor within the policing profession. Fielding (1988) alluded to organizational competence and competence as insufficient or, not applicable to public policy work. Fielding (1988) theorized that the basis of organizational competence is experiential and that it is only through the work that public policy learn the craft. Associated with that theory, Fielding (1988) suggested that a prescriptive definition of competence is unlikely to change policing. Leadership can be found in practice as early as the 1800s even supposing it was not until the 1980s that a collective effort to promote culturally competent practitioners emerged (Carrizales et al., 2016).

Leadership may be more prominent as it relates to policing as the multi-cultural community's public policy serve do not resemble those of what policing faced when Fielding (1988) conducted his study. Public policy often is called to multicultural and Black communities to address problems. The research proposes that many public policies who do not belong to multicultural communities have a weak understanding of the culture residing within. Solutions to these problems by public policy many times do not fall within the culture being unacceptable to community members. These unacceptable solutions complicate and develop more problems.

It is also proposed, because of a lack of leadership the public policy believe that solutions offered are crosscutting. When these solutions are not accepted public policy frequently, default back to the context of establishing law and order. Frustrated at what is seen by public policy as resistance and a lack of respect for authority. The study suggests that the more leadership public policy have, the more solutions available within the varied cultural contexts they serve, ultimately increasing public policy effectiveness. The study investigated the effects of increased leadership on public policy effectiveness in the effort to address the problem described above.

Theoretical assumptions of CPT include the classification scheme of challenges, common problems and system problems. Leadership within the public policy is a systems problem. Eck (2003) asserts that the definition of a particular problem must also include the background, behaviors, and the environment the problem resides in to begin to analyze and address the problem. The study applies and uses this aspect of the CPT in understanding a proposed lack of leadership within the public policy.

Leadership defined as a term despite the fact that it is two words with individual meanings. Dean (2001) defines leadership as learning about history and shared characteristics of different groups using this knowledge to create bridges and increase understanding of other groups. Carrizales et al. (2016) outlines a broader definition describing leadership as a continuum with no absolute fixed endpoint; that is neither an exact bottom for total cultural incompetence nor an exact top measure. Culture may influence how specific communities conduct their daily lives. When one culture intersects with another discord is possible but unknown is; how an increased level of leadership minimizes difference.

Globalization has been mentioned to be a long-standing event facilitating the merging of cultures. This merging of cultures has presented an assortment of problems, in particular for the public policy. In the effort to eliminate or remove the problems resulting in the colliding of cultures, the study explored how leadership allows public policy to engage in their duties with increased effectiveness. The theory that increased leadership leads to greater public policy effectiveness lends itself to the bigger problem of poor public policy-community relationships. As 
described in CPT, the proposed solution presents a scheme for future research and subsequent action. This framework suggests that attention to problem features that are common to all problems should be succinctly understood (Eck, 2003). What the first step in the proposed theory of leadership leading to public policy effectiveness is then to understand it clearly. Explored will be the definitions of leadership within the literature.

Mehrabanfar (2015) suggests that globalization roots in a history of humanity; in fact, cross-cultural transactions in trade and science are the first reasons of human integration started mainly from European confronts with Eastern civilizations such as following Iranian scholar's works. Unlike Dean (2001) and Carrizales et al. (2016) more current definitions include a cognitive function. Von Bergen, Von Bergen, Stubblefield and Bandow (2012) define leadership as the knowledge and skills that one should possess to serve or engage a person from a cultural background different from his/her own. Cooper, Vellurattil, and Quinones-Boex, (2014) define leadership more explicitly; leadership is the ability to provide a service to others with diverse values, beliefs and behaviors, and to tailor their service to clients' social-cultural and linguistic needs.

Cicolini, Pelle, Comparcini, Tomietto, Cerratti, Schim, and Simonetti (2015) provide a detailed definition explaining that; leadership describes the incorporation of personal, cultural diversity experience, awareness, and sensitivity into everyday practice. Glickman, Olsen, and Rowthorn (2015) define leadership as a process, which incorporates cultural awareness, knowledge, skills, encounters, and desires as opposed to an endpoint behavior. The most current definition extrapolated is outlined by Carrizales et al. (2016); defining cultural competency as specific organizational actions and policies that enable the organization to serve its culturally diverse populations efficiently.

Public policy departments are organizations that often serve diverse communities. Literature reveals and suggests that leadership is needed and belongs in policing. Leadership is a developmental process for the individual and the organization (Elton, 2013). Rice (2007) insists that community-policing engagement must develop cultural competency programming within the organization. Fletcher (2014) gives several reasons for promoting and accepting cultural competency in public administrations and public policy; cultural competency recognizes that cultural context in which public encounters occur and, cultural competency presents an opportunity to address the often-inaccurate public service and programs provided to minority populations and service delivery officials are better prepared to do their job (Fletcher, 2014). Finally, Rice (2007) theorizes that as an organizational feature, cultural competency is more than just a part of program content or interpersonal communication styles between public policy and clients.

Among the literature concerning of leadership outlined above, definitions vary. The work of Fielding (1988) can be credited with focusing on leadership in policing in its early stages yet it is weak asserting that it is not applicable to public policy and will not affect policing however Fielding (1988) suggests indirectly that through some unknown vehicle public policy may increase leadership by engaging in policing. Dean (2001) also states that leadership can be learned through studying history to increase knowledge to create bridges by understanding other groups. Dean (2001) similar to Fielding (1988) described that leadership can be learned but both fail to link this learning in an organizational, differences, service or cognitive context.

\section{Discussion}

Literature from Carrizales et al. (2016) provides a background of leadership and explains it as a continuum, which has some applicability. Cooper et al. (2014), Cicolini et al. (2015), Glickman et al. (2015) and particularly Carrizales et al. (2016), literature describes leadership in a more explicit fashion insisting that the definition includes; personal experiences, skills, knowledge, diverse beliefs, values, behaviors and service to clients' needs. It is possible that the inclusion of the aforementioned factors creates a conduit for the study, as these factors can easily be associated to organizational outcomes or effectiveness. Carrizales et al. (2016) despite including some ambiguity in describing leadership in ambiguous terms early makes up ground by insisting that specific organizational actions and policies outline leadership with the end result being the effectiveness of serving culturally diverse populations (communities). This literature was worthy of pairing with the study as the outcomes are expressed, as are clients, multicultural or culturally diverse communities. 
The last component of policing itself is emphasized within the literature of Rice (2007), Elton (2013) and Fletcher (2014). The parallel of defining leadership and its relevance to public policy is pronounced as the three studies essential dyad for public policy organizational effectiveness, congruent with this study. The subsequent study includes the investigation of this aspect of leadership upon public policy effectiveness.

\section{Enhancing leadership}

The suggestion to increase or enhance leadership has been the focus of various literatures. Some literature suggests practice as a vehicle to accomplish this. Rice (2007) mentions that one approach to such has been a call for public policy and other public service providers to practice cultural competency in their engagement and interactions with clients. Sales, Jonkman, Connor and Hall (2013) suggest that whereas ideologies and behaviors that have been held and practiced for years require time to change; short experiences when built over time, could effectively change beliefs.

Literature developed by Sales et al. (2013) also suggests that based on the results of a demographic study, which anticipated increased changes in the United States. It may be necessary for colleges and schools with limited resources to integrate learning opportunities by focusing on specific activities that may enhance targeted components of cultural competency. What is not apparently clear is that if focusing on activities in a learning institution is synonymous to public policy officers learning within their traditional learning organization, the public policy academy.

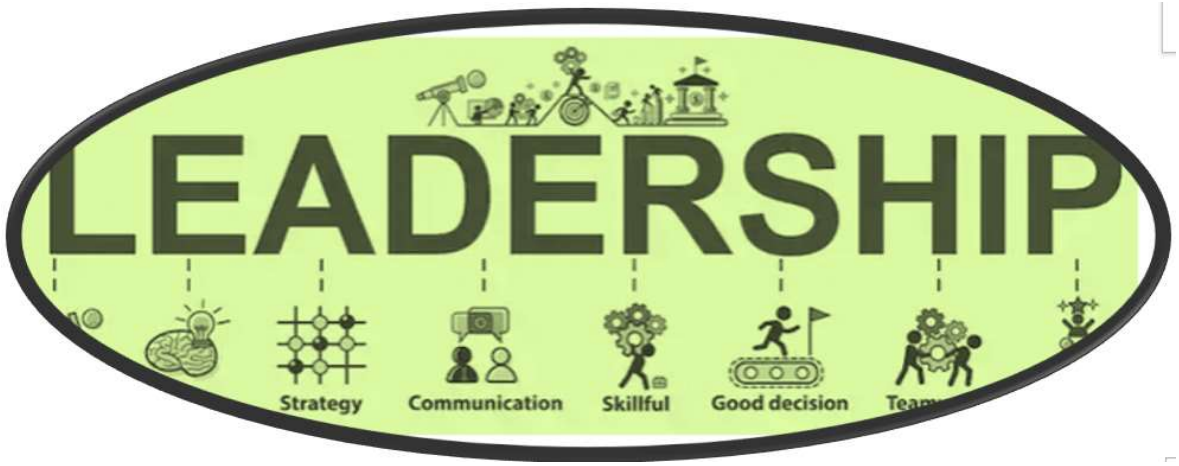

Figure 2. Leadership practical theory

Source: Whaleshares.io.

Enhancing leadership through learning institutions and their subsequent curriculum has been a solid theory in the literature related to leadership although not specific to policing. Sales et al. (2013) concluded that their study supports the threading of activities related to leadership throughout the curriculum and that simple exposure to leadership topics and other interventions significantly impact all cultural domains. Diaz et al. (2015) literature theorizes that professional leadership programs must strengthen self-awareness and improve service by increasing knowledge and leadership skills.

\section{Increasing leadership in public policy}

Literature explicitly related to policing, Fletcher (2014) expresses urgency when she announces that the leadership of public policy organizations must seek to develop leadership programs and forms of institutional socialization that do not reinforce a social dominance orientation or reduce officer identification with the diverse communities they represent. Fletcher (2014) continues to advise that the hiring and recruitment, leadership and development of public policy officers from diverse demographic backgrounds be an essential aspect of moving forward toward cultural competency. Developing or enhancing leadership through various leadership methodologies is suggested given the aforementioned.

Sereni-Massinger, Bawden, \& Rowe (2015) add to the literature of enhancing leadership in policing through leadership but question if knowledge equates to development of leadership mentioning; while students can obtain 
knowledge of a particular culture, or ethnic group through studies in a classroom setting, can they truly develop an understanding of other cultures without having immersed in it. Fletcher (2014) expresses obstacles in enhancing leadership in public policy from a different angle expressing the public policy community has also exhibited reluctance to developing comprehensive cultural competency leadership. Diaz et al. (2015) stress that an essential element for developing leadership of public policy is cultural desire, meaning wanting to rather than having to.

Increasing public policy knowledge base concerning various cultures does provide a basis to address those diverse cultures, however slight. It may not be a plethora of cultural knowledge, but it begins to build a reservoir of cultural understanding within the public policy. It is not reasonable to believe that public policy will have total knowledge of the various cultures in which they serve. Being submerged within different cultures can allow for and increased understanding of that culture, but is not substituted for formal leadership. Getting to the root of public policy resistance in developing leadership leadership is linked to a poor or lack of understanding of various cultures. In some ways a cycle feeding upon itself is apparent. Resistance to leadership because of a lack of understanding of that leadership must be broken by leadership. Leadership must acknowledge the benefits of leadership as mentioned by Diaz et al. (2015) creating a desire and wanting to develop leadership within the agency.

More recent literature suggests that experiencing and interacting with various cultures as opposed to traditional leadership can enhance leadership. Experiential learning provides a pedagogical framework for understanding the connections that exist between education, work, and personal development (Brooks \& Simpson, 2014). Okoro, Odedina and Smith (2015) mention that formal leadership in cultural competency outside of the school curriculum linked with being more skilled in dealing with socio-cultural issues and being more comfortable in handling crosscultural situations. Okoro et al. (2015) added that for most subscales addressing knowledge of public servants and leadership skills; leadership outside of a traditional curriculum is related to higher scores. Sales et al. (2013) literature supports the continued threading of activities related to leadership throughout the curriculum as neither previous exposure to solely leadership topics (traditional leadership) nor exposure significantly impacted all cultural domains.

Enhancing leadership outside of a conventional classroom setting opens up various possibilities. Sales et al. (2013) insisted on enhancing targeted components of leadership; some institutions have described and evaluated culturally relevant activities, such as lectures, case-based assessments, and simulated activities. Carrizales et al. (2016) recommend that educating practitioners through a curriculum that prepares them to work in a culturally diverse society. Finally, Lopez-Littleton and Blessett (2015) even though referencing healthcare professionals indicate that crosscutting curriculum approaches are often broader than traditional classroom-based approaches.

In addition to Okoro et al (2015) and Sereni-Massinger et al. (2015), Sales et al. (2013), Lopez-Littleton et al. (2015) and Carrizales et al. (2016) suggest that traditional learning, relevant activities prepare practitioners for effective cultural interaction. Cultural interaction is an essential component for realizing leadership. Subsequently, a curriculum that is cross cutting is a significant mechanism to enhance cultural competency.

It is unknown if crosscutting approaches related to leadership are congruent with public policy-enhancing leadership despite, how it applies to other professions. Crosscutting suggests that approaches can be varied but also indicates that these approaches may be unknown, not a concise strategy. Similarly identifying or targeting specific components suggests that a critical assessment is conducted locating and focusing on essential elements. Targeting specific components of leadership may be valuable as once public policy engage multicultural communities, they will have a base to operate as a result of these specific identifiable elements. Identifying specific elements of leadership researched after the study found that leadership increases public policy efficacy.

The literature within this subsection is clear, the desire to enhance leadership in the effort to increase effective interaction with diverse persons, organizations, and communities. In general Sales et al. (2013) and Diaz et al. (2015) initially, agree that leadership must ensue to enhance leadership. Both strong studies although, the component of desire and will permeate the literature produced from Diaz et al. (2015). In this sense, it is Diaz et al. (2015) who include organizational aspects whereas leadership may be required to motivate individuals by 
increasing salient points outlining why an increase leadership through leadership is the foundation of increasing leadership. Substantially, it is Sereni-Massinger et al. (2015) who questions the encouragement of enhancing leadership only with traditional learning techniques.

Sereni-Massinger et al. (2015) theorize that additional activities such as increased interactions with culturally diverse persons may address leadership more appropriately that just traditional leadership. This literature along with Okoro et al. (2015) who finds that scores of leaderships can be increased by activities outside of the classroom outline the importance of additional efforts to increase leadership. The two studies along with relevant literature produced by Sales et al. (2013) is progressive in developing mechanisms for increasing leadership and include creativity. These suggestions can be beneficial for public policy who attempt to increase leadership as mentioned earlier; the traditional effectiveness of public policy learning institutions is questionable.

Fletcher's (2014) literature continues to be valuable and applicable as she adds literature towards recognizing the obstacles in policing when attempting to increase leadership. Other literature presented agrees with the theory that leadership and crosscutting curriculum addresses shortcomings in leadership. Additionally, the literature obtained from Sales et al. (2013) Okoro et al. (2015), and Sereni-Massinger et al. (2015) is more appropriate and point to more conducive mechanisms to increase leadership in relationship to this study, in this sense the literature is credible and relevant.

Therefore, based on the extensive review of leadership in all of the various aspects that gives credence to further investigation of how it can assist public policy in addressing gaps in relationships and cultural divides which they face regularly. It is a worthwhile endeavor, as the benefits of increased leadership will provide public policy with a conduit to establishing a credible and legitimate relationship with all citizens including those within multicultural communities. The study researched how and if leadership affects public policy being able to operate more efficiently in their daily operations.

\section{Public policy effectiveness}

The salient feature of organizational effectiveness dates back to the early 20th century. Rivenbark et al. (2013) study asserts that the evolution of performance measurement during the early 1900 s filled a void in the literature by providing an excellent overview of how organizations like the New York Bureau of Municipal Research focused on the mechanics of efficiency and effectiveness measures to support local government operations. Focusing on measurements of efficiency and effectiveness suggests that the importance of both were paramount to organizations succeeded in doing what they were designed to do.

An extensive review of the literature conducted concerning organizational effectiveness revealed relevant information related to the study. Sifting through the literature of public organizations readily revealed various aspects and mechanisms used in achieving effectiveness; organizational structure, organizational behavior, leadership styles and behaviors, workforce planning and performance management subsequently reviewed. Several keywords such as leadership, education and development were added resulting in rich informational literature within the public organizational effectiveness literature. The literature was then extracted and perused. A common theme emerged which captured by Rahmati, Hosseinifard and Alimadadi (2014) stating:

Technological contacts along with competitive and cultural pressures have led to a whirlpool, which can drown any organization. In order to survive and live in such a situation, an organization has to make modifications in itself and its organizational processes (p. 1).

Particularly, effectiveness establishes the degree to which an organization realizes its goals under a given set of conditions (Keeley, 1984). The two studies are separated by decades although Keeley (1984) proposed that while the degree or measurements that an organization realizes its goals also theorizes that a measurement of such can be difficult to accurately obtain. Measurements although challenging may be essential in evaluating effectiveness

Effectiveness is a broad construct, implying a positive value, that remains theoretically obscure, but which tends to be pursued based on organizational goal attainment (Keeley, 1984). It is significant that Keeley's (1984) theory about effectiveness includes components of measurements recognizing the various constructs of different 
organizations. Rivenbark et al. (2013) referenced past research when they claimed that; it was in the 1930s that a major push for the development of performance measures in local government originated from Ridley and Simon (Rivenbark et al. 2013). More importantly for this study, Rivenbark et al. (2013) who contends that their work focused on service areas such as fire, public policy and public works and the goal of their research was to place more emphasis on effectiveness. As the focus on public service and how effectiveness measures address those served, this literature begins to become more relevant to this study.

Government organizations such as public policy departments address a plethora of societal issues and are widely funded by the tax dollars of those they serve. It is then reasonable to understand how Jobson and Schneck (1982) agreeing with Keeley (1984) suggest measuring effectiveness. Jobson and Schneck (1982) theorized that the assessment of government organizations by politicians, government, managers, bureaucrats, and the general public is a vital social process fundamental to the allocation of scarce resources. Keeley (1984) contends that the effectiveness of an organization is a sociopolitical question concerning who wants what and how important is it that the demand be satisfied. Organizational theorists have not often realized that their conceptions of effectiveness fall within the broad scope of social justice (Keeley, 1984), particularly as it pertains to all stakeholders.

Both Keeley (1984) and Jobson and Schneck (1982) assert organizational effectiveness is relevant to the organization's stakeholder's interests. Keeley (1984) mentioned; organizational members share very specific ends and non-conflicting interests in higher levels of goal attainment. Supporting this collaborative theory and literature Pettaway, Waller, \& Waller (2015) mentions that organizational effectiveness is a team effort involving everyone from the head of the organization to entry-level employees engaged on any tasks relating to the operation of the organization, but fails to mention goal attainment specifically. Goal attainment discussed later in this segment although; the aforementioned begins to outline the importance of the study, investigating whom and what increases public policy effectiveness.

Previous literature concerning public policy effectiveness is rarely congruent, but there are some similarities within the literature concerning effectiveness being a complex and multi-component concept. Skogan (1976) proclaimed that effectiveness is high when public policy organizations approach meeting their operational goals. Skogan (1976) who research explored concepts of efficiency and effectiveness in relationship to contemporary demands upon big-city public policy departments collected data based on arrests. The Federal Bureau of Investigations' yearly Uniform Crime Report was used to categorize and select which crimes was the focus of measuring arrests. The crimes are murder, rape, assault, robbery larceny, auto theft and burglary.

Skogan (1976) collected data from 386 cities with populations greater than 50,000 in 1970. The data extracted from the FBI database, which shows crimes and clearance rates of arrests for those crimes. In as much, effectiveness measures, in this case, are based on the rate of arrests made, albeit clearance rates. The relationship between clearance rates, efficacy and resources used (costs), efficiency, was measured. Skogan (1976) found that large city departments, which are efficient, are also effective, converting more crimes to arrests with less organizational effort.

Skogan (1976) research on public policy effectiveness and efficiency was substantial for its period but in comparison to the proposed research here, does not address the problem of effectiveness within the context of community-public policy relations. Skogan (1976) conducted his research shortly after the Civil Rights period where only Black communities and a smaller amount of multicultural communities in which we have today existed. It may be reasonable to suggest that these communities had only a small voice in the community and the feature of stakeholder salience was microscopic as it related to desired public policy behavior.

A dated study, Skogan (1976) study is limited and focused on slim measures, which do not include any aspect of consideration for the community let alone the relationship between public policy and the community. Although prominent for its time it does not relate to the public policy operations of today illuminated in this study. In fact, the narrow focus on clearance rates through arrests disregarding community interests and the culture of those communities increase community dissatisfaction with the public policy. 
Jobson and Schneck (1982) originally pronounced that there could be no global, univariate, ultimate, or overall measure of organizational effectiveness. Jobson and Schneck (1982) continued expressing that organization can be simultaneously efficient and ineffective on some differencing criteria from multiple goals and constituents, and simple dimensions of effectiveness may be independent. The purpose of Jobson and Schneck's (1982) study was to identify, select, and specify a variety of organizational effectiveness criteria then measure these criteria using the goal approach to organizations. The goal approach suggests that organizations view effectiveness criteria in multidimensional terms.

In a study conducted in 18 Alberta municipalities that contracted Royal Canadian Mounted Public policy (RCMP) for public policy services. A 109-item questionnaire was sent to all RMCP officers in the municipalities resulting in a $70 \%$ response rate, yielding 182 officers. Furthermore, 125 residents of the 18 communities were selected to participate in the study. The inhabitants of the survey included three groups, council members, business and professional persons and randomly chosen citizens from throughout the 18 communities. The aim of the surveys was to extract views of the public policy from their nationals in addition to the RCMP views of effectiveness. The results of the study are composed of two parts.

The results of the Jobson and Schneck (1982) study explained from the point of view that public policy effectiveness is highly contingent upon reducing crime. The study found that citizens felt that the public policy were more effective when the crime rate was low. Particularly, citizen perceptions of local crime were found to be positively related to the crime rate and negatively related to environmental safety (Jobson \& Schneck, 1982). Contrarily, RCMP officers concluded that they felt more effective when the citizens in the community they served needed their services. The study also found that perceived effectiveness is not positively related to increased crime, perceived effectiveness increases as the crime rate drops (Jobson \& Schneck, 1982).

As described earlier in this literature review, the single measurement of crime rate does not consider other important aspects of an organization's operation, which assist, in the overall effectiveness of that organization. One important aspect of Jobson and Schneck (1982) study discusses community interaction with the public policy. Jobson and Schneck (1982) insist that the solve rate of crimes be strongly related to community participation, and thus the inference could be made that community involvement enhances the ability to solve crimes. Plus, increased community interaction could be a major mechanism through which the public policy gather critical information that leads to the apprehension of criminals (Jobson \& Schneck, 1982).

This pinnacle realization by Jobson and Schneck (1982) creates a pathway to investigate how public policy can increase community interaction, established only by pursuing a better relationship between the two, which is in line with this study. The proposed study investigates how a better relationship between public policy and community leads to public policy effectiveness although not only for the benefit of reducing crime rates as, public policy effectiveness in this present day is much more sophisticated.

More recent literature suggests that effectiveness is more involved than one narrow measure as Knight (2014) specifically referencing policing insisted that effectiveness is a complex concept with many dimensions. It may be the complexity and multiple dimensions of effectiveness that cause public policy organizations difficulty in obtaining organizational effectiveness. Organizational effectiveness outcomes are particularly pronounced for the public policy since common performance measures in the public policy are affected by multiple confounding factors (Ramchunder \& Martins, 2014). Effectiveness is the degree to which an organization achieves the purposes for which it is established (Knight, 2014). Organizational effectiveness involves an organization's mission that is its purpose; basing the measurement of organizational effectiveness on the unique ability the organization displays to ensure success (Chuang et al. (2015). Hence, the promotion of a positive vision of organizational effectiveness requires that the organization empower and support the needs and development of its employees (Pettaway et al., 2015).

Organizational effectiveness then hinges on the specific organization mission, vision, and values. Values are the convictions that guide the behavior of a public policy officer and the entire organization adding their style that reflects the performance of public policy agencies (Reynoso \& Tovar, 2014). Public policy values fluctuate from organization to organization and get better constantly, serving as a basis for the public understanding of policing, 
to guide the judgments of successful public policy officers and seek understanding of what the public policy agency is trying to accomplish (p. 829).

The understanding of public policy effectiveness within their respective public policy agencies is dependent upon those organizational specific variables espoused by the organization. Reynoso and Tovar (2014) asserted that if there are variables related to the effectiveness of public policy agencies, then the hypothesis that there are organizational variables related to the effectiveness of the public policy is accepted. These variables are not easily translated into public policy effectiveness although, embedded in the mission, values, and vision that must be modeled and institutionalized by leadership. CPT, the theoretical framework for the prospective study, suggests that deconstructing an overall problem into smaller ones in the effort to succinctly understand the problem allows for subsequent research in the pursuit of appropriate solutions. The identification of variables that relate to public policy effectiveness parallels the CPT and is what the study is designed to determine.

The complexity of creating and carrying out the strategic decisions of an entire organization demand more skill and effort than a single leader can effectively provide (Colbert et al., 2014), this applies in particular given the shortcomings of public policy leadership. CPT suggests the identifying of problems in the pursuit of addressing them even supposing this theoretical foundation explicitly explains that describing this process is far simpler that it exists in the real world (Eck, 2003). The effectiveness of public policy is a complicated endeavor as repeatedly expressed in this literature review. Adding the various aspects of leadership to pursuing effectiveness complicates the proposed study but does not diminish its relevance.

Knight (2014) found inadequate knowledge transfer to, and education of, public policy leaders on the value of strategic management and the measurement of organizational performance that is necessary to improve organizational performance. A significant knowledge base is paramount in understanding public policy effectiveness or the lack of such. The upper echelons perspective proposes that the experiences, values, and personalities of a public policy executive along with their command staff shape their interpretation of the environment, which in turn influences strategic choice and organizational effectiveness (Colbert et al., 2014).

Summarizing the section, the literature extracted by Rivenbark et al. (2013) and Keeley (1984) which are two compelling studies that establish the understanding of organizational effectiveness, its prescribed use and some contention of why it is necessary to measure effectiveness. It is significant that Rivenbark et al. (2013), Skogan (1976) and Jobson and Schneck (1982) present relevant literature that directly focuses on government organizations and public policy. Jobson and Schneck (1982) suggest that measurements are complex and exclusive to specific organizations. While this assertion allows for discussions which may be exclusive to each agency searching for appropriate measurements, it is contrary to what the study is asserting, which are professional and system-wide measurements of effectiveness that are cross-cutting throughout all organizations.

Relevant literature from Ramchunder, and Martins (2014) and Knight (2014) pronounce the importance but complexity of public policy organizations as they seek measurements of effectiveness. Reynoso and Tovar (2014) and Colbert et al. (2014) continue to add essential literature to the study mentioning that many considering variables and the importance of leadership transferring what is exclusively relevant to public policy organizations are significant although; somewhat contrary to the study insisting that organizational measurements of effective can be cross-cutting. In this specific example, it does not diminish the credibility of the two studies. Traditionally public policy organizations insist that their prescriptions for organizational effectiveness be unique, they too are an organization and this section presents literature concerning the importance of efficiency and supports how confusing individual measures can be. The literature outlined above establishes the need for a crosscutting and overall organizational measure of organizational effectiveness, which this study will pursue.

\section{Effectiveness measurements and models}

Organizational effectiveness of the public policy is closely related to public perception. Performance measures that include measures relevant to satisfying citizens and enhancing public policy organizational legitimacy can influence public policy effectiveness (Knight, 2014). Boateng, (2014) also mentions that prior studies have found evidence suggesting that public trust influences public policy efficiency and legitimacy. Sereni-Massinger et al. 
(2015) mention that to make a difference truly, public policy needs to respect those they serve. Knight (2014) references past studies asserting that public policy behavior (treatment towards citizens) influences public policy legitimacy and this important empirical and theoretical finding links citizen individual attitudes and perceptions with objective crime prevention outcomes.

The studies mentioned above establish a need for the proposed study. Through the predictor variables, diversity leadership, and leadership presented, the overall purpose of the intended research is to search for the means to create a better relationship between the community and the public policy. The investigation of the effects of diversity leadership and leadership to effectiveness is to ascertain if a relationship exists which increases the effectiveness of public policy in their duties particularly in communities they serve. The focus of multicultural communities presents the biggest challenge. Achieving public policy effectiveness in multicultural communities, it is reasonable then to accept that if those techniques used are then applicable to other communities where the relationship is less than optimum if desired.

Performance-based measures will not only increase employees' performance but also improve a quality of service so citizens can be satisfied (Tozlu \& Tuzen, 2016). Boateng (2014) insists that public trust in the public policy be a vital ingredient to public policy operation and public policy effectiveness. It has been tradition particularly in policing and the public sector that narrow measurements continue to be monitored painting only a partial picture of how the organization is operating and its effectiveness and employee behavior. Sparrow (2015) outlines this when he wrote:

Executives then often seemed surprised when the narrow range of information monitored produces partial or inadequate interpretations of what is really happening and when the narrow performance focus drives behaviors that turn out to be perverse and contrary to the public interest. (p. 7)

An overall model of public policy organizational effectiveness is established to develop the performance measures striving for effectiveness. Nadkami and D'souza (2015) explain that there are four main models of organizational effectiveness: the Goal Approach, the Systems Approach, Competing Values Approach and the Strategic Consistency Approach. Fluidity within these models is apparent although attempts to narrow them down have been established by Reynoso and Tovar (2014) mentioning that positively there are four variables related to the effectiveness of public policy organizations: organizational development, axiological development, human development and technological development. Ultimately, effectiveness is the end goal and as Pettaway et al. (2015) contends a positive impression of the effectiveness of an organization requires: employee involvement and buy-in, a reciprocal relationship between employees and the organization, secure and professional work environment, strong organizational commitment to continuous improvement.

The model and variables above applied to professional organizations including the public policy profession and referred to as new business models. Increasingly, public-sector organizations are adopting new business models, which can encourage greater emphasis on tangible benefits and improvements for citizens shifting the balance of power to the front line, where services are provided (Micheli, Schoeman, Baxter, \& Goffin, 2012). Nadkami and D'souza (2015) references Systems approach, Reynoso and Tovar (2014), organizational development and Pettaway et al. (2015) suggest a reciprocal relationship between employees and the organization. The commonality of the three studies and their theories, variables and models suggest organizational effectiveness is a system, contrary to a unilateral approach to individual or specific goals. Nadkami and D'souza (2015) concluded that organizations with the least rankings at the national level, were following the Goal Attainment Approach chiefly, as the problems encountered in defining who's goals are to be followed, the purpose of the goals and which time frame is for those aims.

Nadkami and D'souza (2015) address a particularly important aspect of why public policy effectiveness has not been congruent nationally as previously stated in this literature review. Today, crime measurements (crime rate) are not the only measurement of the public policy, nor are it the standard to be used to determine the success or effectiveness of public policy (Reynoso \& Tovar, 2014). Obviously, crime rate cannot be employed unilaterally to address public policy effectiveness. 
Emphasizing the development of new models geared for benefits and improvement of services for citizens is what the study targets. Furthermore, establishing measurements based on organizational operations and commitments surpass single measurement criteria for public policy synonymous to a goal approach theory. The public policy profession will continue to be ineffective if each public policy department sets their goals unilaterally without any consistent framework that includes consideration of the citizens whom they serve. Employing the System Approach when establishing effectiveness measurements is beneficial in two forms.

The System Approach is inclusive of entire systems that include organizational aspects such as, roles of leadership, innovative technology, motivation, resource capabilities and customer service. Secondly, a system approach will provide a national measurement of public policy effectiveness, which can be used to rank and compare public policy organizations nationwide. National measurements and rankings are beneficial for public policy executives, political officials and citizens of various communities, leading to public policy transparency. The foundational theory, CPT is predicated on solving problems through research, which in the proposed study seeks to investigate increased public policy effectiveness through diversity leadership and leadership resulting in better service to communities and their citizens.

Arguing that defining the effectiveness of an organization solely regarding the goals achieved is only a partial measure of effectiveness (Nadkami \& D'souza, 2015). Nadkami and D'souza (2015) stated that Systems Approach is inclusive of the pronounced theories, variables and models indicated above by Reynosa and Tovar (2014) and Pettaway et al. (2015). The System Approach to effectiveness views the organization as an opens system, whereby the organization requires inputs, engages in transformation processes and generates outputs (Nadkami \& D'souza, 2015). This is in line with Ashraf's (2012) System Resource Approach, which espouses the salient feature of inputs and explains effectiveness from viewpoints residing in the ability to obtain necessary resources from the environment outside the organization. We can relate inputs and resources from the external environment to communities that public policy organizations serve.

The research investigates two important and complex predictor variables predicted on the premise that they increase effectiveness albeit by way of addressing the entire system of a public policy organization. The Systems Approach or closely related System Resource Approach emphasizes systems perspectives, which examine various variables such as relations with the environment (community) to assure continued receipt of inputs and favorable acceptance of outputs (public policy service). Also, the flexibility of response to environmental changes; the efficiency with which the organization transforms inputs to outputs (community involvement); the clarity of internal communications; the level of conflicts among groups; and the degree of employee satisfaction (Nadkami \& D'souza, 2015).

Addressing variables and enabling flexibility relate to both diversity leadership and leadership. It is reasonable to conclude that the understanding of the two contexts will evolve as has been demonstrated through the literature. The flexibility of public policy desired under this premise is also viewed as a problem within the overall problem of public policy effectiveness, in line with the foundational CPT. Observing public policy organizations through a systems perspective in the manner above is beneficial for obtaining public policy efficacy and furthermore, it can be recommended for all agencies. The systems perspective gives support for measuring public policy effectiveness as a professional organization and not the traditional narrow measurements used in the past that are exclusive to public policy.

\section{Methodology}

Methodology refers to the general logic and theoretical perspective of a study, whereas methods only refer to specific strategies, procedures, and techniques of analyzing and interpreting data (Long, 2014). Agreed by scholars, there are three research methodologies: quantitative, qualitative, and mixed-methods (Long, 2014). Using qualitative research methods are popular when a researcher is interested in understanding the "why" behind people's behavior (Rosenthal, 2016), which is not applicable in this study. Although proponents of mixed methods research have suggested areas in which mixed methods approach is superior to a single method design, there has been intense debate regarding whether or not it is even appropriate to combine multiple methods that are often radically different paradigmatic assumptions (Verikatesh et al., 2013). One of the limitations of mixed-methods 
research is the typical amount of time and effort involved in collecting, analyzing and validating both quantitative and qualitative data (p.48).

Because this research will be used to construct a dissertation, time is of the essence; it rules out the time intensive mixed-methods research approach. This research study will employ a quantitative approach; quantitative research is a means for testing scientific theories by examining the relationship among variables (Ingham-Broomfield, 2014). Ingham-Broomfield (2014) includes a more in-depth explanation when she wrote:

Quantitative research attempts to establish statistically significant relationships, addresses questions by measuring and describing, is based on objective measurement and observation, and is concerned with correlation and causation (p. 33).

The nature of the study was to investigate the relationship between two predictor variables (diversity leadership and leadership) and the criterion variable, public policy effectiveness. Quantitative research is grounded in the positivist position, the concept of an objective reality where truths exist and can be studied independently of the knower and knowledge (Long, 2014; Quick \& Hall, 2015; Ingham-Broomfield, 2014).

This design allowed the variable(s) to be measured or manipulated in the study (Ingham-Broomfield, 2014). In conclusion, quantitative research has a long tradition of assessing and reporting validation, traditional approaches to validation in quantitative validity, measurement validity, and inferential validity (Verikatesh et al., 2013). In sum quantitative research is idea for this study.

The use of quantitative research has been used may times in the past when investigating diversity, its effects and outcomes in the general workforce and within the public policy. These quantitative studies include studies by Guajardo (2015), Alhejji et al. (2015), Fan (2016) and Chin et al., (2016). Additionally, the following quantitative studies investigating the variable public policy effectiveness have used engaged in regression models; Ward (2013), Knight (2014), Ludwig \& Johnston (2016), MacDonald, Fagan, \& Geller (2016) and Posick \& Policastro (2018).

CPT strongly suggests that a research approach to public policy problems be able to investigate diver multiple questions, which undoubtedly considers multiple variable comparisons. Eck (2003) expresses this mentioning that public policy research should focus on the four issues examined within the theory. The problem investigated in the study was public policy effectiveness. Multiple variables relate to public policy effectiveness even supposing for this research study we investigated the relationship of two, diversity leadership and leadership.

\section{Instrumentation}

In today's socio-economic environment, quantitative research utilizes as a preferred methodology by perfusion researchers' due to issues relating to time, financial considerations and the simplicity of accessing quantifiable information and data (McCusker \& Gunaydin, 2015). This type of research might use surveys, questionnaires, or polls and then uses mathematically based methods to analyze the collected data (Ludwig \& Johnston, 2016). The importance of survey research cannot be underestimated, emphasized by Ludwig and Johnston (2016) in this passage:

Survey research requires a validated survey, meaning the survey actually measures what it is supposed to measure. (p. 714)

Surveys collect critical responses, particularly in a problem-solving framework. CPT emphasizes that systemic evaluations of problem-solving responses be included in problem-solving protocols (Eck, 2003). As previously mentioned, surveys, questionnaires and polls can be used to analyze data. Secondly, evaluating data can use the same mechanism. The study required that the collected data retrieved to be analyzed and evaluated. Particularly the Culturally Competent Self-Assessment Questionnaire (CCSAQ) instrument which is a self-assessment instrument. These self-assessment responses must be analyzed, evaluated and synthesized to improve our understanding of participant's level of leadership ascertaining if the solution was most appropriate for the problem of increasing public policy effectiveness. 
The methodology was preferable to evaluate the degree of diversity leadership and leadership predicts public policy effectiveness. Public policy leadership's diversity leadership initiatives and leadership were predictor variables in the study. Public policy effectiveness was the criterion variable. Even though this research investigated current practices of public policy organizations, it also recommends an in-depth look at the professional development of public policy leadership to include other viable leadership traits that mimic successful leadership in organizations outside of policing. The selected quantitative research approach is inclusive of several components. Methodology deals with the methods, tools, and measurement in a scientific field and also with a systemic examination of the employed methodical practices (Verikatesh et al., 2013).

The study was designed to establish if the two predictor variables, diversity leadership, and leadership are related to public policy effectiveness. Finding that the two predictor variables to be related to increase public policy effectiveness, they must play a integral part in a comprehensive strategy in addressing the overall problem of poor public policy and citizen relationships. The relationship between public policy and community even in its mediocrity is an obstacle in achieving effective policing as described in this literature review.

The tool that was selected for this study was be a combination of three validated tools. The Organizational Effective Inventory (OEI), the Cultural Diversity Inventory (CDI) and the Leadership Self-Assessment Questionnaire (CCSAQ). The OEI used in its entirety and supplemented by selected components of the CDI and CCSAQ. All three of these tools have been used successfully in past research studies. The OEI was used to examine organizational effectiveness in Watt \& Piotrowski (2008) and Zeine, Boglarsky, Blessinger, \& Michel (2014). The CDI has been implemented in research studies such as DeVoe, McMillan, Zimmerman, \& McGrew (1996) subsequent to receiving education and leadership of diversity to examine the learning outcomes of the aforementioned above. Teasley, Archuleta and Miller (2014), Choi, Suh, Park, Park, \& Fernandez (2015) and Doherty, Maher, Ivanikiw, Hales, Lebiecki, \& Wren (2017) all used the instrument CCSAQ in their prominent studies allowing the participants to conduct a self-assessment of leadership.

Authors believe that the prior study (Delanoy, N \& Kasztelnik K) showed that the business open big data analytics can support international innovative leadership process by using the novel technology.

\section{Conclusion}

History and its literature provide many examples of theories of public policy effectiveness. The paramilitary organization of public policy departments, the ideology and life-style of public policy men, and the operational definition of "good public policy work" continue to reflect, however, the crime fighting functions of public policy agencies (Skogan, 1976). The Justice Department Office of Community Oriented Policies prepared a Guide for Creating Performance Indicators for Public policy organizations, which provided a structured methodology for creating performance indicators of public policy organizations whose framework, suggests integrated implementation of the law (Reynoso \& Tovar, 2014). Kiehl, (2013) closer to the intentions of this study finds that internal measure was preferred for evaluating organizational effectiveness of public policy.

These traditional and relatively recent measurements are no longer amicable for assessing $21^{\text {st }}$ Century policing. The globalizing and more competitive world require one to have a more functional public sector and public employees' system (Tozlu \& Tuzen, 2016). Even though studies such as Kiehl (2013) recognized that no one measure of organizational effectiveness fits for all situations. There are more specific critics who discuss inefficiency; lacking a hortative and fair reward system, insufficient leadership and equipment, work overload, limited carrier ways and monotone and inflexible working types (Tozlu \& Tuzen, 2016). Public policy are less effective than they could be because they have developed a narrow identity as society's crime fighter, which is a commensurate narrow focus of the performance measures that public policy monitor (Knight, 2014).

There are several factors that can be included in the search of increasing public policy effectiveness. Diversity leadership is a key component of diversity initiatives, demonstrating stronger effects on cognitive-based and skillbased outcomes than affective-based outcomes (Kalinoski, Steele-Johnson, Peyton, Leas, Steinke, \& Bowling, 2013). Cultural competency presents an opportunity to address the often-inaccurate public service and programs provided to minority populations (Fletcher, 2014). It was not known if the leadership of public policy agencies 
learning outcomes of diversity leadership initiatives and the level of leadership of leadership predict public policy organizational effectiveness. Garib (2013) concluded that a more advanced study would advantageously include improved methodological activities resulting in some objective data concerning organizational outcomes of diversity leadership. While Carrizales et al. (2016) assert that future research may look at the integration of cultural competency into public policy organizations and its service delivery making it a more effective public administration. Furthermore, this study examined if the leadership of public policy agencies high level of learning outcomes of diversity leadership initiatives combined with high level of leadership of leadership predicts to a higher level of public policy organizational effectiveness than either leadership's learning outcomes of diversity leadership initiatives or leadership alone. Diaz et al. (2015) suggest that research among interdisciplinary professionals is needed to identify and facilitate a more culturally competent and diversity educated workforce in order to possibly increase effective practices. The target population for the study was AACPD in Maryland specifically, Sergeants Lieutenants, Captains, Majors, Commanders, Assistant Chiefs, Deputy Chiefs, and Chief from which data was extracted in the detailed step by step fashion described in the following section, Chapter 3 .

Funding: self-funded.

Authors' contributions: conceptualization, Dr. Kasztelnik, Dr. Brown; data curation, Dr. Kasztelnik, Dr. Brown; formal analysis, Dr. Kasztelnik, Dr. Brown; funding acquisition, Dr. Kasztelnik, Dr. Brown; investigation, Dr. Kasztelnik, Dr. Brown; methodology, Dr. Kasztelnik, Dr. Brown; project administration, Dr. Kasztelnik, Dr. Brown; resources, Dr. Kasztelnik, Dr. Brown; software, Dr. Kasztelnik, Dr. Brown; supervision, Dr. Kasztelnik, Dr. Brown; validation, Dr. Kasztelnik, Dr. Brown; visualization, Dr. Kasztelnik, Dr. Brown; writing - original draft, Dr. Kasztelnik, Dr. Brown; writing - review \& editing, Dr. Kasztelnik, Dr. Brown.

\section{References}

1. Alhejji, H., Garavan, T., Carbery, R., O'Brien, F., \& McGuire, D. (2015). Diversity leadership programme outcomes: A systematic review. Human Resource Development Quarterly. doi: doi.org/10.1002/hrdq.21221.

2. Alcott, C. (2012). Reforming the force: An examination of the impact of the operational sub-culture on reform and modernization within the public policy service. British Journal of Community Justice, 10(1), 5. doi: 10.1177/0032258X15579357.

3. Archibald, P. C., Daniels, K., \& Sinclair, M. (2017). Social work analysis of social change reflecting renewed plans for effective urban community policing Baltimore City. Urban Social Work, 1(1), 5-19. doi: 10.1891/2474-8684.1.1.5.

4. Ashraf, G. (2012). A review on the models of organizational effectiveness: A look at cameron's model. International Education Studies, 5(2), 80. doi: 10.5539/ies.v5n2p80.

5. Belgrave, J. (2015). Critical synthesis package: leadership self-assessment questionnaire-service provider version (CCSAQ-SP). MedEdPORTAL Publications, 11:10180. doi: 10.15766/mep 2374-8265.10180.

6. Ben-Porat, G., Yuval, F., \& Mizrahi, S. (2012). The challenge of diversity management: public policy reform and the Arab minority in Israel. Policy Sciences, (3). 243. doi: 10.1007/s11077-012-9154-x.

7. Beu, A., \& Nepravishta, A. (2013). Relationship between the public policy educational formation system and public security. European Journal of Sustainable Development, 2(4), 173. Available at: https://www.ecsdev.org/images/conference/siICSD2013/beu\%20173-184.pdf.

8. Birzer, M. L. (1999). Public policy leadership in the 21 st century. FBI Public policyBulletin, 68, 16-19. Available at: http://shodhganga.inflibnet.ac.in/bitstream/10603/104400/15/15 references.pdf.

9. Boateng, F. D. (2014). Restoring the lost hope: A multidimensional approach for building public trust in the public policy. Journal of the Institute of Justice and International Studies, (13), C1. Available at: https://search.proquest.com/openview/6baac9559643d200d26a0844061ed04d/1?pqorigsite $=$ gscholar \&cbl $=18750 \&$ diss $=y$.

10. Bohm, C. (2013). Cultural flexibility in ict projects: A new perspective on managing diversity in project teams. Global Journal of Flexible System Management, 14(2) 115-121. doi: 10.1007/s40171-013-0037-6.

11. Brecher, N. (2012). Diversity delivers: Four tips for embracing differences. Journal of Property Management 
[serial online] 77(3), 24. Available at: https://www.questia.com/magazine/1G1-292010425/diversitydelivers-four-tips-for-embracing-differences. Accessed August 18, 2016.

12. Brooks, L., \& Simpson, L. (2014). Experiential learning in higher education: Implications for improving employability of fcs graduates. Journal of Family and Consumer Sciences, 106(2), 16. Available at: https://core.ac.uk/download/pdf/237214054.pdf.

13. Brown, K., \& Coulter, P. (1983). Subjective and objective measures of public policy service delivery. Public Administration Review, 43(1), 50-58. Available at: http://www.jstor.org/stable/975299 doi:1.

14. Burke, L., M. Teague, Ward, D., and Worrall, A. (2016). 'Probation occupational cultures for the future?' British Journal of Community Justice 14(1), 29-48. Available at: https://derby.openrepository.com/handle/10545/608617.

15. Campbell, M. (2016). Getting to grips with statistics: understanding variables. British Journal of Midwifery, 24(10), 738. Available at: https://ir.ua.edu/bitstream/handle/123456789/3350/file 1.pdf?sequence=1\&isAllowed=y.

16. Carrizales, T., Zahradnik, A., \& Silverio, M. (2016). Organizational advocacy of cultural competency Initiatives: Lessons for public administration. Public Administration Quarterly, 40(1), 126. Available at: https://paq.spaef.org/article/1642/Organizational-Advocacy-of-Cultural-Competency-Initiatives-Lessonsfor-Public-Administration.

17. Census: U.S. Census Bureau (2017). Quick facts anne arundel county Maryland. Available at: https://www.census.gov/quickfacts/annearundelcountymaryland.

18. Cezarino, L. O., Junior, F. H., \& Correa, H. L. (2012). Organizational performance evaluation using systems thinking: A study in Brazilian chemical organizations models. Systemic Practices and Action Research, 25(1), 81-92. doi:10.1007/s11213-011-9198-4.

19. Chin, J. L., Desormeaux, L., \& Sawyer, K. (2016) making way for paradigms of diversity leadership. Consulting Psychology Journal: Practice And Research, 68(1), 49-71. doi:10.1037/cpb0000051.

20. Choi, H., Suh, E. E., Park, C. G., Park, J., \& Fernandez, E. (2015). Reliability and validity of a Korean version of the cultural awareness scale (K-CAS). Korean Journal of Adult Nursing, 27(4), 4479. doi: 10.7475/kjan.2015.27.4.472.

21. Chuang, H. C., Liu, M. D., \& Chen, Y. Y. (2015). The effects of human resources capability and internal customer satisfaction on organizational effectiveness. Internal study of Distributed Sensor Networks, 2015110. doi: doi.org/10.1155/2015/835194.

22. Cicolini, G., Pelle, C. D., Comparcini, D., Tomietto, M., Cerratti, F., Schim, S. M., \& Simonetti, V. (2015). Leadership among Italian Nurses: A multicentric survey. Journal of Nursing Scholarship, 47(6), 536. Available at: http://search.proquest.com/openview/6baac9559643d200d26a0844061ed04d/1?pq-origsite= gscholar\& cbl $=18750 \&$ diss $=\mathrm{y}$.

23. Cocchiara, F., Connerley, M., \& Bell, M. (2010). A gem for increasing the effectiveness of diversity leadership. Human Resource Management, 49(6), 1089-1106. doi: 10.1002/hrm.20396.

24. Cooke, R. A. (2009). From organizational effectiveness inventory. Plymouth, MI: Human Synergistics. Copyright 2017 by Human Synergistics. Available at: https://www.mdpi.com/2076-3417/10/10/3454/pdf.

25. Cooke, R. A., \& Lafferty, J. C. (1987). From culture for diversity inventory. Plymouth, MI: Human Synergistics. Copyright 2017 by Human Synergistics. Available at: http://scholar.google.com/ citations? user=byd3JGkAAAAJ\&hl=en.

26. Colbert, A. E., Barrick, M. R., \& Bradley, B. H. (2014). Personality and leadership composition in top management teams: Implications for organizational effectiveness. Personnel Psychology, 67(2), 351. doi:10.1111/peps.12036.

27. Cole, J. C., Ito, D., Chen, Y. J., Cheng, R., Bolognese, J., \& Li-McLeod, J. (2014). Impact of Alzheimer's disease on caregiver questionnaire: internal consistency, convergent validity, and test-retest reliability of a new measure for assessing caregiver burden. Health \& Quality Of Life Outcomes, 12(1), 1-20. doi:10.1186/s12955-014-0114-3.

28. Coleman, T. G. (2012) "A Model for improving the strategic measurement and management of policing: The Public policy Organizational Performance Index (POPI)." PhD Dissertation, University of Regina: Saskatchewan, Canada. Available at: https://www.passengerprotect-protectiondespassagers.gc.ca/cnt/ 
rsrcs/pblctns/2015-s034/index-en.aspx.

29. Cooper, L., Vellurattil, R. P., \& Quinones-Boex, A. (2014). Pharmacy students' perceptions of leadership encounters during practice experiences American Journal of Pharmaceutical Education, 78(2). Available at: https://www.ajpe.org/content/78/2/31.abstract.

30. Corrales, Carlos, Corrales, \& Ledezma. (2018). How to address the data quality issues in regression models: A guided process for data cleaning. Symmetry, Vol 10(4), p 99(2018), (4), 99. Doi: https://doiorg.lopes.idm.oclc.org/10.3390/sym10040099

31. Cunningham, G. B. (2012). Diversity leadership in intercollegiate athletics. Journal of Sport Management, 26(5), 391-403. doi: $10.1016 / \mathrm{S} 0742$.

32. de Almeida Vieira Monteiro, A.T., \& Fernandes, A. B. (2016). Leadership in mental health nursing: Validity and internal consistency of the Portuguese version of the multicultural mental health awareness scale-MMHAS. BMC Psychiatry, 16. Available at: https://www.researchgate.net/publication/303279190 Cultural competence in mental health nursing Validity and internal consistency of the Portuguese ve rsion of the multicultural mental health awareness scale-MMHAS.

33. Dean, R. (2001). The myth of cross-leadership. Families in Society: The Journal of Contemporary Social Services, 82(6), 623-630. Available at: https://static1.squarespace.com/static/56fd7e0bf699bb7d 0d3ff82d/t/593ab7c3893fc0f72c38e2b0/1497020355936/Myth+of+Cultural+Competence.pdf.

34. DeGeorge, B. V. (1995). Equal employment opportunity in a climate of managing diversity: An institutional study of personnel processes of the Pennsylvania state public policy (Order No. 9611276). Available from ProQuest Dissertations \& Theses Global.(304220853). Retrieved from; https://lopes.idm.oclc.org/login?url= http://search.proquest.com/docview/304220853?accountid $=7374$.

35. Delanoy, N., Kasztelnik, K. (2020). Business Open Big Data Analytics to Support Innovative Leadership Decision in Canada. Business Ethics and Leadership, 4(2), 56-74. http://doi.org/10.21272/bel.4(1).5674.2020 .

36. DeVoe, McMillan, Zimmerman, \& McGrew. (1996). Infusing a multicultural component into coaching education. Journal of Instructional Psychology,23(1), 14-20. Available at: https://lopes.idm. oclc.org/login?url=http://search.ebscohost.com/login.aspx?direct=true\&db=psyh\&AN=1996-06051$003 \&$ site $=$ eds-live \&scope $=$ site.

37. Diaz, C., Clarke, P. N., \& Gatua, M. W. (2015). Leadership in rural nursing education: Are we there yet? Nursing Education Perspectives, 36(1), 22. Doi: 10.5480/12-1066.1.

38. Dwyer, B., Eddy, T., \& LeCrom, C. W. (2014). Destined to succeed? Team identification and the attributional bias of NFL fans. Journal of Sport Behavior, 37(4), 333. Available at: https://psycnet.apa.org/record/201445994-002.

39. Eck, J. E. (2003). Public policy problems: The complexity of problem theory, research and evaluation. Crime prevention studies, 15, 79-114. Available at: https://live-cpop.ws.asu.edu/sites/default/files/library/ crimeprevention/volume $15 / 04$ eck problem theory.pdf.

40. Ekechukwu, A., Hendricks, W., White, K., Liabastre, A., Archuleta, M., \& Hoover, M. (2009). Validation of analytical methods and instrumentation for beryllium measurement: review and summary of available guides, procedures, and protocols. Journal of occupational \& Environmental Hygiene, 6(12), 766-774. doi:10.1080/15459620903260536.

41. Elton, J. S. (2013). An explanatory study of leadership: Examining cross-cultural adaptability in peace officers (Doctoral dissertation, University of Akron). Available at: https://pdfs.semanticscholar.org/c3cd/d3 6563913c2f5b5d0ac873c880cf627afe74.pdf.

42. Ewoh, A. I. (2013). Managing and valuing diversity: Challenges to public managers in the 21 st century. Public Personnel Management, 42(2), 107-122. doi: 10.1177/009 1026013487048.

43. Fan, M. D. (2016). Violence and public policy diversity: A call for research, Brigham Young University Law Review, 4, 875-914. Available at: https://digitalcommons.law.byu.edu/cgi/view content.cgi? article $=2992 \&$ context $=$ lawreview.

44. Faulkner, R., Freeman, G., \& Izzard, M. (2012). University school of education promoting diversity awareness and initiatives. Professional Educator, 36(1). Available at: https://files.eric.ed.gov/ 
45. Federal Bureau of Investigation. (2013). Full-time public policyemployees. FBI.GOV. Information retrieved on December 11, 2016 from https://ucr.fbi.gov/crime-in-the-u.s/2013/crime-in-the-u.s.-2013/tables/table-74.

46. Fengquing, Z., \& Jiangtao, G. (2016). A p-value model for theoretical power analysis and its applications in multiple procedures. BMC Medical Research Methodology, 161-7. doi:10.1186/s12874-016-0233-0.

47. Ferreira, M. R., \& Proença, J. F. (2015). Strategic planning and organizational effectiveness in social service organizations in Portugal. Management: Journal of Contemporary Management Issues, 20(2), 1. Available at: https://hrcak.srce.hr/index.php?show=clanak\&id_clanak_jezik=221541.

48. Fielding, N. (1988). Competence and culture in the public policy. Sociology, 22(1), 45-64. Available at: http://journals.sagepub.com/doi/10.1177/0038038588022001004.

49. Fletcher, M. N. (2014). Cultural competency in law enforcement: Assessing leadership levels among college campus public policy departments. Research Papers, 504. Available at: https://opensiuc.lib.siu.edu/cgi/viewcontent.cgi?article $=1647 \&$ context=gs_rp.

50. Furberg, C. D., \& Soliman, E. Z. (2008). Double-blindness protects scientific validity. Journal Of Thrombosis \& Homeostasis, 6(2), 230. doi:10.1111/j.1538-7836.2008.02836.x.

51. Freeman, G., Izzard, M., Faulkner, R., \& Charles, J. (2012). University school of education promoting diversity awareness and initiatives. Professional Educator,36(1), 1-7. Available at: http://files.eric.ed.gov/fulltext/EJ989 519.pdf.

52. Gaber, N., \& Wright, A. J. (2016). Journal of Urban Health, 93(1), 88. Doi: https://doi.org/10.1007/s11524015-0009-6.

53. Gale, N. K., Heath, G., Cameron, E., Rashid, S., \& Redwood, S. (2013). Using the framework method for the analysis of qualitative data in multi-disciplinary health research. BMC medical research methodology, 2013, 13(1), 1. Available at: https://bmcmedresmethodol.biomedcentral.com/articles/10.1186/1471-2288-13-117.

54. Garib, G. (2013). Diversity is in the eye of the beholder. The Psychologist-Manager Journal, 16(1), 18-32. doi: $10.1037 / \mathrm{a} 0094733$.

55. Giacobbi, P. R. (2002). Survey construction and analysis, Part II: Establishing reliability and validity. Athletic Therapy Today, 7(5), 60-61. Available at: https://cpass.wvu.edu/files/d/acc9eae4-5cbe-4c01-89d93bd5a6d6a81b/giacobbi-vita fall-2019.pdf.

56. Glenn, R. W., Panitch, B. R., Barnes-Proby, D., Williams, E., Christian, J., Lewis, M. W., \& Brannan, D. W. (2003). Leadership the 21st Century public policy officer: redefining public policy professionalism for the Los Angeles public policy department. Santa Monica, CA: Rand. Available at: http://journals.sagepub.com/doi/10.1177/1098611115604449.

57. Glickman, L. B., Olsen, J., \& Rowthorn, V. (2015). Measuring the cross-cultural adaptability of a graduate student team from a global immersion experience. Journal of Cultural Diversity, 22(4), 148. doi: 10.1016/j.physio.2015.03.3241.

58. Goertzen, M. J. (2017). Introduction to quantitative research and data. Library Technology Reports, 53(4), 12-18. Available at: https://www.arcjournals.org/pdfs/ijsell/v7-i7/4.pdf.

59. Goldstein, H. (1979). Improving policing: A problem-oriented approach. Crime and Delinquency, 25(2), 236258. doi: $101177 / 001112877902500207$.

60. Gong, Y., Yang, S., Ma, H., \& Ge, M. (2018). Fuzzy regression model based on geometric coordinate points distance and application to performance evaluation. Journal of Intelligent \& Fuzzy Systems, 34(1), 395-404. https://doi-org.lopes.idm.oclc.org/10.3233/JIFS-171433.

61. Guajardo, S. A. (2015). Assessing organizational effectiveness and workforce diversity: An application of data envelopment analysis to New York City agencies. Public Personnel Management, 44(2), 239-265. doi: $10.1177 / 0091026015575179$

62. Gundelach, B. (2014). In diversity we trust: The positive effect of ethnic diversity on out group trust. Political Behavior, 36, 125-142. doi:10.1007/s111109-013-9220-x.

63. Halla, A. L. F. (2014). Assessment of the need for cultural competency leadership within crisis negotiation leadership in the state of Arizona (Order No. 1558983). Available from ProQuest Dissertations \& Theses Global. (1556553855)

64. Ho-Kyung, H., Seong Woo, C., \& JuSung, J. (2015). Relationships among multicultural sensitivity, 
multicultural education awareness, and level of multicultural educations practice of South Korean teachers. KEDI Journal Of Educational Policy, 12(1), 107-126. Available at: https://scholarworks.bwise.kr/ssu/handle/ 2018.sw.ssu/9828.

65. Hurst-Wagner, M., \& Oswald, M. E. (2012). Impact of deception detection errors on public's trust in the public policy. Legal And Criminological Psychology, 17(2), 294-306. doi: 10.111/j.2044-8333.2010.02008.x

66. Hurtado, S., \& DeAngelo, L. (2012). Linking diversity and civic-minded practices with student outcomes: New evidence from national surveys. Liberal Education, 98(2), 14-23. Available at: https://www.aacu.org/publications-research/periodicals/linking-diversity-and-civic-minded-practicesstudent-outcomes-new.

67. Ingham-Broomfield, R. (2014). A nurses' guide to quantitative research. The Australian Journal of Advanced Nursing, 32(2), 32. Available at: https://www.ajan.com.au/archive/Vol32/Issue2/4Broomfield.pdf.

68. Jobson, J. D., \& Schneck, R. (1982). Constituent views of organizational effectiveness: Evidence from public policy organizations. The Academy of Management Journal, (1), 25. Doi: https://doi.org/10.5465/256022.

69. Kalinoski, Z. T., Steele-Johnson, D., Peyton, E. J., Leas, K. A., Steinke, J., \& Bowling, N. A. (2013). A metaanalytic evaluation of diversity leadership outcomes. Journal of Organizational Behavior, 34(8), 1076-1104. doi:10.1002/job.1839

70. Kataria, A., Rastogi, R., \& Garg, P. (2013). Organizational effectiveness as a function of employee engagement. South Asian Journal of Management, 20(4), 56-73. Available at: https://lopes.idm.oclc.org/login?url=http://search.proquest.com/ docview/1519059074?accountid=7374

71. Katz, J., \& Miller, F. (2016). Defining diversity and adapting inclusion strategies on a global scale. OD Practitioner. Summer, 48(3); 42-47. Available at: https://kjcg.squarespace.com/s/ODP-V50No4-Miller-andKatz.pdf.

72. Keeley, M. (1984). Impartiality and participant-interest theories of organizational effectiveness. Administrative Science Quarterly, 29(1), 1-25. Available at: https://www.jstor.org/stable/2393077.

73. Keung, E. K., \& Rockinson-Szapkiw, A. J. (2013). The relationship between transformational leadership and cultural intelligence: A study of international school leaders. Journal of Education Administration, 51(6), 836-854. Available at: https://www.tib.eu/en/search/id/emerald\%3Adoi 10.1108\%252FJEA-04-20120049/The-relationship-between-transformational-leadership/.

74. Kiehl, K. R. (2013). Examining perceptions of organizational effectiveness of public policy departments and leadership styles of public policy supervisors (Order No. 3569890). Available from ProQuest Dissertations \& Theses Global. (1370761178). Available at: https://opes.idm.oclc.org/login?URL=http://search.proquest .com/docview/1370761178?accountid=7374.

75. King, E., Dawson, J., Kravitz, D., \& Gulick, L. (2012). A multilevel study of the relationships between diversity leadership, ethnic discrimination and satisfaction in organizations. Journal of Organizational Behavior, 33(1), 5-20. doi: 10.1002/job.728.

76. Knight, G. M. (2014). Calls for service and public policy effectiveness: The role of performance measurement systems. Thesis ( $\mathrm{PhD}$ Doctorate), Griffith University, Brisbane. Available at: https://www120.secure.griffith.edu.au/rch/items/06938197-1233-40da-aeb1-c33b6235c6ab/1/.

77. Kroeger, A., \& Weber, C. (2015). Developing a conceptual framework for comparing social value creation. Academy Management Review, 401543-70. doi: 10.5465/amr.2012.0344.test.

78. Lai, Y. (2013). Policing diversity: Determinants of White, Black, and Hispanic attitudes toward public policy. El Paso, TX: LFB Scholarly. Available at: http://citeseerx.ist.psu.edu/viewdoc/download?doi= 10.1.1.903.6790\&rep $=$ rep $1 \&$ type $=$ pdf.

79. Lee, S. A., Chancellor, R., Chu, C. M., Rodriguez-Mori, H., \& Roy, L. (2015). Igniting diversity: Actionable methods and Ideas for advancing diversity in LIS education in the US. Journal of Education for Library and Information Science, 56, S47. Available at: https://pdfs.semanticscholar.org/7e2a/f9c3d6bflfd7 6d607caeec8fe479c50b10b2.pdf.

80. Legrand, T., \& Bronitt, S. (2012). Policing to a different beat: Measuring public policy performance. In policing and security in practice, pp. 1-19. Palgrave Macmillan UK. Available at: https://link.springer.com/chapter/10.1057/9781137007780_1.

81. Lim \& Kim. (2018). Development of regression models considering time-lag and aerosols for predicting 
heating loads in buildings, Advances in Civil Engineering. Article ID 4878021. doi: https://doi.org/10.1155/2018/4878021.

82. Lindsey, A. a., King, E., Hebi, M., \& Levine, N. (2015). The impact of method, motivation, and empathy on diversity leadership effectiveness. Journal of Business \& Psychology, 30(3), 605-617. http://www.mikkihebl.com/uploads/9/0/2/3/90238177/79.pdf.

83. Long, H. (2014). An empirical review of research methodologies and methods in creativity studies (20032012). Creativity Research Journal [serial online]. n.d.; 26(4), 427-438. Available from: Social Sciences Citation Index, Ipswich, MA. Accessed August 20, 2016. Available at: https://www.tandfonline.com/doi/abs/10.1080/10400419.2014.961781.

84. Lopez-Littleton, V., \& Blessett, B. (2015). A framework for integrating leadership into the curriculum of public administration programs. Journal Of Public Affairs Education, 21(4), 557-574. Available at: https://www.researchgate.net/publication/326026154_A Framework for Integrating Cultural Competenc $\mathrm{y}$ into the Curriculum of Public Administration Programs.

85. Ludwig, R., \& Johnston, J. (2016). How to build a quantitative research project. Radiologic Technology, 87(6), 713-715. Available at: https://pubmed.ncbi.nlm.nih.gov/27390243/.

86. MacDonald, J., Fagan, J., \& Geller, A. (2016). The Effects of local public policy surges on crime and arrests in New York City. PLoS ONE 11(6): e157223. Doi: https://doi.org/10.1371/journal.pone.0157223

87. Mason, J. L. (1995). Leadership self-assessment questionnaire: A manual for users. Portland, OR: Research and Leadership Center on Family Support and Children's Mental Health, Portland State University. Available at: https://www.pathwaysrtc.pdx.edu/pdf/CCSAQ.pdf.

88. Matherne, C., III, Hill, V., \& Hamilton, J. B., III. (2016). A taxonomy of behavior in organizational settings: The implications of moral identity congruence. Journal of Applied Management and Entrepreneurship, 21(3), 73. Available at: https://journals.sagepub.com/doi/abs/10.1177/2158244020933336.

89. Maurya, M. K., \& Agarwal, M. (2015). Relationship between supportive leadership, mental health status and job satisfaction of civil public policy constables. Journal of the Indian Academy of Applied Psychology, 41(3), 103. Available at: http://link.springer.com/content/pdf/10.1007\%2Fs11896-017-9230-4.pdf.

90. McCallister, Grance, \& Scarfone. (2010) Guide to protecting the confidentiality of personal identifiable information (PII): Recommendations of the National Institute of Standards and Technology. Special Publication 800-122. Available at: https://csrc.nist.gov/publications/detail/sp/800-122/final.

91. McCusker, K., \& Gunaydin, S. (2015). Research using qualitative, quantitative or mixed methods and choice based on the research. Perfusion, 30(7), 537-542. doi: 10.1177/0267659114559116

92. Meares, T.L. (2017). The path forward: Improving the dynamics of community-public policy relationships to achieve effective public policies, Faculty Scholarship Series, 5171. Available at: https://mentis.uta.edu/dashboard/file/download/id/211047.

93. Mehrabanfar, E. (2015). Globalization streams in futures studies. Informatica Economica, 19(3), 96. Available at: https://econpapers.repec.org/RePEc:aes:infoec:v:19:y:2015:i:3:p:96-106.

94. Merkey, L. (2015). Building trust and breaking down the wall: The use of restorative justice to repair public policy-community relationships. Missouri Law Review, 80(4), 1133. Available at: http://search.proquest.com/openview/ad6a7330dc9387473f3b2ba75e0e4289/1?pqorigsite $=$ gscholar $\& \mathrm{cbl}=18750 \&$ diss $=\mathrm{y}$.

95. Micheli, P., Schoeman, M., Baxter, D., \& Goffin, K. (2012). New business models for public-sector innovation: Successful technological innovation for government. Research-Technology Management, 55(5), 51. Available at: http://wrap.warwick.ac.uk/68709/.

96. Mohaffyza, M., Sulaiman, N., Lai, C., \& Salleh, K.. (2015). Measuring the validity and reliability of research Instruments. Procedia - Social and Behavioral Sciences, 204, 164-171. Doi: 10.1016/j.sbspro.2015.08.129.

97. Nadkami, D., \& D'souza, M. (2015). A study of the success value of the four approaches to organizational effectiveness in 18 companies in the Indian service and industry sectors. SIES Journal OF Management [serial online] March, 11(1), 59-76. Available at: http://www.iosrjournals.org/iosr-jbm/papers/Conf.170162017/Volume\%201/11.\%2077-89.pdf. Accepted August 21, 2016.

98. Nair, G. K., Luqman, A., Vadeveloo, T., Shanmuggam, S., \& Iskandar, H. (2013). Public confidence in public policy competency to combat crime. Asian Social Science, 9(4), 58. Available at: 
SocioEconomic Challenges, Volume 4, Issue 4, 2020

ISSN (print) - 2520-6621, ISSN (online) - 2520-6214

https://www.researchgate.net/figure/Disparity-between-perception-level-and-actual-crime-level-in-the-

United-Kingdom-Source fig1 286996245.

99. Okoro, O., Odedina, F., \& Smith, W. T. (2015). Determining the sufficiency of leadership instruction in pharmacy school curriculum. American Journal of Pharmaceutical Education, 79(4). Available at: https://www.ncbi.nlm.nih.gov/pmc/articles/PMC4469016/.

100. Park, J., \& Park, M. (2016). Qualitative versus quantitative research methods: Discovery or justification? Journal of Marketing Thought, 3(1), 1-7. doi:15577/jmt2016.03.01.1

101. Pearson-Goff, M., \& Herrington, V. (2013). Public policy Leadership: A Systematic Review of the Literature Policing, 8: 14-26. Available at: https://www.researchgate.net/publication/270841177_Police Leadership A Systematic Review of the Literature.

102. Pemberton, C. A. (2012). A "how-to" guide for the education thesis/dissertation process. Kappa Delta Pi Record, 48(2), 82-86. doi: 10.1080/00228958.2012.680378.

103. Peersman, G. (2014), Overview: Data collection and analysis methods in impact evaluation, UNICEF. Available at: http://devinfolive.info/impactevaluation/img/downloads/ .Data collection and Analysis ENG.pdf.

104. Pettaway, L., Waller, L., \& Waller, S. (2015). Surveying organizational effectiveness: A case study from the United Emirates. Journal of Organizational Culture, Communications \& Conflict, 19(3), 45-54. Available at: http://aurak.ac.ae/publications/Surveying-organizational-effectiveness-A-case-study-from-the-UnitedArab-Emirates.pdf.

105. Popescu, S., \& Rusko, R. (2012). Managing diversity in public organizations. Global Business and management Research: An international Journal 4(3-4), 235-247. Available at: http://www.gbmrjournal.com/pdf/vol.\%204\%20no.\%203/Popescu\%20\&\%20Rusko,\%202012.pdf.

106. Posick \& Policastro (2018). Victim-injury, emotional distress, and satisfaction with the public policy: Evidence for a victim-centered, emotionally-based public policy response. Criminal Justice and Criminology, Georgia Southern University. Available at: http://connection.ebscohost.com/c/articles/94992130/victiminjury-emotional-distress-satisfaction-police-evidence-victim-centered-emotionally-based-police-response.

107. Pozveh, A. Z., \& Karimi, F. (2016). The relationship between organizational climate and the organizational silence of administrative staff in education department. International Education Studies, 9(6), 120-129. Available at: http://www.ccsenet.org/journal/index.php/ies/article/view/53742.

108. Prajapati, B., Dunne, M. C. M., \& Armstrong, R. A. (2010). Sample size estimation and statistical power analyses. Optometry Today. Available at: https://research.aston.ac.uk/en/publications/sample-sizeestimation-and-statistical-power-analyses.

109. Quick, J., \& Hall, S. (2015). Part three: The quantitative approach. Journal of perioperative Practice, 25(10), 192-196. Available at: https://scholarworks.waldenu.edu/cgi/viewcontent.cgi? article=8 355\&context $=$ dissertations.

110. Rahmati, M. H., Hosseinifard, S. M., \& Alimadadi, A. (2014). Investigating effectiveness of in-service leadership in the public sector. Iranian Journal of Management Studies, 7(2), 291. Available at: https://unitec.researchbank.ac.nz/bitstream/handle/10652/3507/MBus 2016 Vanida\%20SINGHAVARA\% 20\%2B.pdf? sequence $=7 \&$ is Allowed $=\mathrm{y}$.

111. Ramchunder, Y., \& Martins, N. (2014). The role of self-efficacy, emotional intelligence and leadership style as attributes of leadership effectiveness. SA Journal of Industrial Psychology, 40(1), 1. Available at: https://www.researchgate.net/publication/271301356 The role of self-effiicacy e motonal intelligence and leadership style as atributes of leadership effectiveness.

112. Reaves, B.A. (2015). Local public policy departments, 2013: Personnel, policies and practices. Washington, D.C.: U.S. Department of Justice. Available at: https://www.nap.edu/read/24928/chapter/11.

113. Reynoso, L. F., \& Tovar, L. A. (2014). Organizational variables in effectiveness of public policy. International Review of Management and Business Research, 3(2), 827. Available at: http://citeseerx.ist.psu.edu/viewdoc/download?doi=10.1.1.679.8358\&rep=rep1\&type=pdf.

114. Rice, M. F. (2007). Promoting cultural competency in the public administration and public service delivery: Utilizing self-assessment tools and performance measures. Journal of Public health Affairs Education, 13, 41-57. doi:10.1080/15236803.2007.12001466. 
115. Rice, S. K., \& White Roberts, M. D. (Eds.). (2010). Race, ethnicity, and policing: New and essential readings. New York: New York University Press. Available at: https://www.amazon.com/Race-EthnicityPolicing-Essential-Readings/dp/0814776167.

116. Rivenbark, W. C., Roenigk, D. J., \& Noto, L. (2013). Navigating efficiency and effectiveness relationships across local government services: Another step toward strategic resource management. Journal of Public Budgeting, Accounting \& Financial Management, 25(4), 675. Available at: https://www.sog.unc.edu/about/faculty-and-staff/william-c-rivenbark.

117. Rosenthal, M. (2016). Methodology Matters: Qualitative research methods: Whey, when, and how to conduct reviews and focus groups in pharmacy research. Currents in Pharmacy, Teaching And Learning, 8, 509-516. Available from: https://daneshyari.com/article/preview/352945.pdf. Accessed August 20, 2016.

118. Sales, I., Jonkman, L., Connor, S., \& Hall, D. (2013). A Comparison of educational Interventions to enhance cultural competency in pharmacy students. American Journal of Pharmaceutical Education, 77(4). Available at: https://www.ajpe.org/content/77/4/76.abstract.

119. Schlosser, M. D. (2011). Evaluating the Midwest public policy academy's ability to prepare recruits to public policy in a diverse multicultural society. Unpublished doctoral dissertation, University of Illinois at Urbana-Champaign. Available at: https://www.ideals.illinois.edu/handle/2142/26225.

120. Schlosser, M., Sundiata, C. J., Vaigoi, M., \& Neville, H. (2015). Improving policing in a multicultural society in the United States: A new approach. International Journal of Criminal Justice Sciences, 10(1), 115121. Available at: $\mathrm{http} / / \mathrm{www}$. ijcjs.com/pdfs/schlosseretalijcjs2015vol10issue1.pdf.

121. Seedall, R. B., Holtrop, K., \& Parra-Cardona, J. R. (2014). Diversity, social justice, and intersectionality trends in c/mft: A content analysis of three family therapy journals, 2004-2011. Journal of Marital and Family Therapy, 40(2), 139. Available at: https://pubmed.ncbi.nlm.nih.gov/24754858/.

122. Seong, J., \& Doo-Seung, H. (2013). Gender diversity: How can we facilitate its positive effects on teams? Social Behavior and Responsibility, 41(3), 497-508. doi: 10.2224/sbp.2013.41.3.497.

123. Sereni-Massinger, Bawden, \& Rowe, (2015) Policy Point - Counterpoint: mandating public policyto receive annual certification in cultural diversity through critical thinking. International Social Science Review, 91(2). Available at: https://digitalcommons.northgeorgia.edu/issr/vol91/iss2/21/.

124. Simmons, J. M., \& Greenwell, T. C. (2014). Differences in fan-family conflict based on an individual's level of identification with a team. Journal of Sport Behavior, 37(1), 94. Available at: https://www.researchgate.net/publication/334784359 Exploring_Football_Fan_Engagement A Case_Stud y_in_Customer_Experience_Innovation.

125. Simons, S., \& Rowland, K. (2011). Diversity and its impact on organizational performance: the influence of diversity constructions on expectations and outcomes. Journal of Technology Management \& Innovation, 6(3), 171-182. doi: 10.4067/S0718-27242011000300013.

126. Skogan, W. G. (1976). Efficiency and effectiveness in big-city public policy departments. Public administration review, 278-286. Available at: https://www.researchgate.net/publication/319932693 No 12 THE POLICE SERVICE DIVERSITY AND ORGANISATIONAL OUTCOMES A REPORT OF A SYSTEMATIC_REVIEW.

127. Smith, C. L., \& Wiser, M. (2015). On the importance of epistemology-disciplinary core concepts interactions in LP's. Science Education, 99(3), 417-423. doi: 10.1002/sce.21166.

128. Solakoglu, O. (2016). Trust in public policy: A comparative study of Belgium and the Netherlands. International Journal of Criminal Justice Sciences, 11(1), 45. Available at: https://www.sascv.org/ijcjs/pdfs/solakogluijcjs2016voll1issue1.pdf.

129. Soldan, Z., \& Nankervis, A. (2014). Employee perceptions of the effectiveness of diversity management in the Australian Public Service: Rhetoric and reality. Public Personnel Management, 43(4), 543-584. Available at: https://journals.sagepub.com/doi/abs/10.1177/0091026014533093.

130. Sparrow, M.K. (2015). Measuring performance in a modern public policy organization, Psychosociological Issues in Human Resource Management, 3(2), 17-52. Available at: https://link.springer.com/article/10.1186/s40163-019-0108-x.

131. Stone, C., \& Travis, J. (2013). Toward a new professionalism in policing. Journal of the Institute of Justice and International Studies, (13), B1. Available at: https://www.ncjrs.gov/pdffiles1/nij/232359.pdf. 
132. Steinheider, B., \& Wuestewald, T. (2008). From the bottom-up: sharing leadership in a public policy agency. Public policy Practice \& Research, 9(2), 145-163. doi: 10.1080/15614 260802081303.

133. Stura, C., \& Lepadatu, D. (2014). The black box of diversity in sports teams: Converging factors and theoretical explorations. International Journal of Sports, 4(2), 47-57. Available at: http://ijr.cgpublisher.com/product/pub.191/prod.196.

134. Teasley, Archuleta \& Miller (2014) Perceived levels of leadership for school social workers: A followup study. Journal of Social Work Education, 50(4), 694-711, doi:10.1080/10437797.2014.947903

135. Tiwana, N., Bass, G., \& Farrell, G. (2015). Public policy performance measurement: An annotated bibliography. Crime Science, 4(1), 1-28. doi:10.1186/s40163-014-0011-4.

136. Tozlu, A., \& Tuzen, A. (2016). A glance to the new rules of thumb in the context of new public management. Gumushane University Electronic Journal of the Institute of Social Science, 7(15), 24-38. doi: 10.17823 /gusb. 253

137. Tyler, T. (1994). Governing amid diversity. The effect of fair decision-making procedures on the legitimacy of government. Law \& Society Review, 28(4), 809-831. Available at: https://escholarship.org/content/qt24t012n9/qt24t012n9_noSplash_3fe02b837f6752d894cad50cbd0957a1.p df?t=pe601c.

138. Twycross, A., \& Shields, L. (2004). Validity and reliability - What's it all about? part 2 reliability in qualitative studies Paediatric Nursing, 16(10), 36. Available at: https://pubmed.ncbi.nlm.nih.gov/15641352/.

139. Ullah, A. (2014). Analysis of leadership initiatives undertaken for professional development of library professionals in Pakistan. Library Philosophy and Practice, 1 . Available at: https://www.academia.edu/9621508/Analysis_of training_initiatives undertaken for professional develop ment of library professionals in Pakistan.

140. Vasiliou, M., Kouta, C., \& Raftopoulos, V. (2013). The use of the leadership assessment tool (Ccatool) in the community of nurses; the pilot study and test-retest reliability. International Journal of Caring Sciences, 6(1), 44-52. Available at: https://ktisis.cut.ac.cy/handle/10488/7838.

141. Verikatesh, V., Brown, S., \& Balla, H. (2013). Bridging the qualitative-quantitative divide: guidelines for conducting mixed methods research in information systems. MIS Quarterly, 37(1), 21-54. Available at: http://www.vvenkatesh.com/wp-content/uploads/2015/11/Venkatesh_Brown_Bala_MISQ forthcoming.pdf.

142. Vess, L. (2016). Examining race and racism in the university: A class project. Radical Teacher, 106. https://doi.org/10.5195/rt.2016.307.

143. Von Bergen, C., Von Bergen, B., Stubblefield, C., \& Bandow, D. (2012). Authentic tolerance: between forbearance and acceptance. Journal of Cultural Diversity, 19(4), 111-117. Available at: https://www.readbyqxmd.com/read/23362691/authentic-tolerance-between-forbearance-and-acceptance.

144. Wallace, D. H. (2013). Professionalism and legitimacy for criminal justice. Journal of the Institute of Justice \& International Studies, 13. Available at: http://ppc.unl.edu/wp-content/uploads/2010/03/Herian-Thenational-governors-association-and-opposition-to-homeland-security-policy-2010.pdf.

145. Ward, K. L. (2013). Assessing public policy-citizen communication by identifying perceptions of community policing styles and effectiveness (Order No. 3570216). Available from ProQuest Dissertations \& Theses Global. (1372006196). Available at: https://lopes.idm.oclc.org/login?url=http://search.proquest.com/ docview/1372006196? accountid=7374.

146. Weisburd, E., \& Eck, E. (2010). What can public policy do to reduce crime, disorder and fear? The ANNALS of the American Academy of Political and Social Science,593(1), 42-65. doi: 10.11770002716203262546 .

147. Woods, S. (2014). Does the race of public policy officers' matter? Public policy officers on interactions with citizens and public policy procedures (Order No. 3665295). Available from ProQuest Dissertations \& Theses Global. (1637644197). Available at: https://lopes.idm.oclc.org/login?url=http://search.proquest. com/docview/1637644197? accountid=7374.

148. White, C., Louis, B., Persky, A., Howell, D., Griffin, L., Simmons-Yon, A., \& Scolaro, K. (2013). Institutional strategies to achieve diversity and inclusion in pharmacy education. American Journal of Pharmaceutical Education, 77(5), 1-8. doi: 10.5688/ajpe77597.

149. Wilson, C. P., \& Wilson, S. A. (2014). Are we there yet? Perceptive roles of African American public 
policy officer in small agency settings. Western Journal of Black Studies, 38(2), 123-133. Available at: https://scholarworks.waldenu.edu/cgi/viewcontent.cgi?article $=4537 \&$ context $=$ dissertations.

150. Young, J., Spicer, D., Dunnett, D., \& Putt, J. (2014). Highly commended - public policy/social research award: Community engagement public policy officers (CEPOs): improving community safety and making a difference in remote Aboriginal and Torres Strait Islander communities. Market \& Social Research, 22(2), 81. Available at: http://search.proquest.com/openview/6baac9559643d200d26a0844061ed04d/1?pqorigsite $=$ gscholar $\& \mathrm{cbl}=18750 \&$ diss $=\mathrm{y}$.

151. Zakin, A. (2012). Hand to hand: Teaching tolerance and social justice one child at a time. Childhood Education, 88(1), 3. Available at: https://www.tandfonline.com/doi/abs/10.1080/00094056.2012.643709.

152. Zeine, Boglarsky, Blessinger, \& Michel. (2014). External adaptability of higher education Institutions: The use of diagnostic interventions to improve agility. International Higher Education Teaching Change Management: An International Journal 13 (4), 1-12. Available at: https://nanopdf.com/download/curriculum-vitae-rana-zeine pdf.

153. Zimny, K. (2012). Teaching public policy cultural diversity: Using action research to improve the Midwest public policy academy's preparation of recruits to public policy in a diverse society (Order No. 3570721). Available from ProQuest Dissertations \& Theses Global. (1429506210). Available at: https://lopes.idm.oclc.org/login?url=http://search.proquest.com/docview/1429506210?accountid=7374

154. Zounemat-Kermani, Mohammad, Scholz, \& Miklas. (2014). Modeling of dissolved oxygen. Applying stepwise regression and a template-based fuzzy logic system. Journal of Environment Engineering, 140, 6976. doi: 10.1061/(ASCE)EE.1943-7870.0000. 